\title{
Quantitative assessment of energy and resource recovery in evolutionary wastewater treatment plants based on Plant-Wide simulations
}

\author{
T. Fernández-Arévalo ${ }^{(a)}$, I. Lizarralde ${ }^{(a)}$, S.I. Pérez-Elvira ${ }^{(b)}$, J.M. Garrido ${ }^{(c)}$, S. Puig ${ }^{(d)}$, M. Poch ${ }^{(d)}$, P. Grau ${ }^{(a)}$ \\ and E. Ayesa ${ }^{(a)}$ \\ (a) Ceit-IK4 and Tecnun (University of Navarra), 15 Paseo Manuel de Lardizabal, San Sebastián 20018, Spain \\ (E-mail: tfernandez@,ceit.es; ilizarralde@ceit.es; pgrau@,ceit.es; eayesa@ceit.es) \\ (b) Department of Chemical Engineering and Environmental Technology, University of Valladolid, C/Dr. \\ Mergelina, s/n, 47011 Valladolid, Spain (E-mail: $\underline{\text { sarape@iq.uva.es) }}$

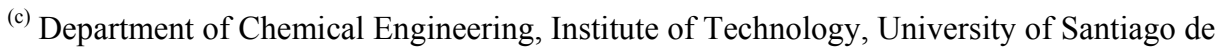 \\ Compostela, 15782 Santiago de Compostela, Spain (E-mail: juanmanuel.garrido@usc.es ) \\ (d) LEQUIA, Institute of the Environment, University of Girona, Campus Montilivi, C/Maria Aurèlia \\ Capmany, 69, E-17003, Girona, Catalonia, Spain (E-mail: sebastia@lequia.udg.cat; \\ manuel.poch@udg.edu)
}

\begin{abstract}
The growing development of technologies and processes for resource treatment and recovery is offering endless possibilities for creating new plant wide configurations or modifying existing ones. However, the configurations' complexity, the interrelation between technologies and the influent characteristics turned decision-making in a complex or unobvious process. In this frame, the Plant-Wide Model library presented in this paper allows a thorough, comprehensive and accurate analysis of different plant configurations that are basic aspects in decision-making from an energy and resource recovery perspective. In order to demonstrate the potential of the library and the need to run simulation analyses, this paper carries out a comparative analysis of evolutionary WWTP, from a techno-economic point of view. The selected layouts were (1) a conventional WWTP based on a modified version of the Benchmark Simulation Model No. 2, (2) an upgraded or retrofitted WWTP, and (3) a new WRRF concept denominated as C/N/P decoupling WWTP. The study was based on a preliminary analysis of the organic matter and nutrient energy use and recovery options, a comprehensive mass and energy flux distribution analysis in each configuration in order to compare and identify areas for improvement, and a cost analysis of these plants for different influent COD/TN/TP ratios. The plant layouts proposed in this paper are just a sample of the possibilities offered by current technologies. Even so, the library presented here is generic and can be used to construct any other plant layout, provided that a model is available.
\end{abstract}

\section{Keywords}

Energy and Resource recovery; Global mass and energy balance; Model-based assessment; Plant-Wide simulations;

\section{INTRODUCTION}

The purpose of the design and upgrade of conventional waste(water) treatment plants (WWTPs) has traditionally been to remove the residual organic compounds and nutrients contained in the water to fulfil quality standards. Resource or energy recovery was focused exclusively on obtaining energy from the biogas produced in anaerobic sludge digestion. This biogas production can supply from a quarter to half of the energy requirements for a WWTP with activated sludge (AS) process (Crawford et al., 2010; McCarty et al., 2011; Puchongkawarin et al., 2015), which needs between 0.3 and $0.6 \mathrm{kWh} \mathrm{m}^{-3}$ treated water (Foley et al., 2010) to fulfil the energetic needs of the plant. Nevertheless, this value is only one tenth of that associated to the heat of combustion of organic compounds contained in the wastewater (McCarty et al., 2011; Shoener et al., 2014; Kokabian et al., 2015). Hence, if a greater proportion of this energy were recovered, treatment plants could become self-sufficient and producers of energy (Logan, 2004; Guest et al., 2009).

Recent concerns about climate change or sustainability have led to an increasing awareness of the importance of resource recovery, energy minimization and environmental impact assessment, which in turn has resulted in tightening effluent standards. Under this changing context, a new paradigm 
has emerged in which municipal wastewater (MWW), traditionally considered to be a pollution problem and an energy- and chemical-intensive activity with excess sludge disposal issues (Gude, 2015), is starting to be thought of as a continuous and sustainable source of chemical energy and resources (Frijns et al., 2013). As a result, WWTPs are now considered to be Wastewater Resource Recovery Facilities (WRRF) from which valuable products like chemicals, nutrients (mainly phosphorus, P), bioenergy (methane from anaerobic digestion) and bio-products can be obtained (Keller, 2008, Guest et al., 2009). To make this change possible, the water sector is developing new and innovative treatment technologies, such as energy-efficient nutrient removal or recovery technologies with Anammox, struvite crystallisers, phototropic bacteria, high rate algae systems, sludge pre-treatment processes, or systems for the production of microbial polymers.

The most immediate step for getting this goal is the updating of existing plants in order to reduce overall operating costs and recover resources. Thanks to the incorporation of new technologies or different plant layouts, energy self-sufficient WWTPs is a feasible goal (Jeppsson et al., 2007). Proof of this comes from the Strass and Wolfgangsee-Ischl WWTPs in Vienna (Wett et al., 2007; Nowak et al., 2011). As stated in the work of Batstone et al. (2015), currently there are two extended philosophies to address the transition from WWTPs to WRRF's. One is the low energy mainline (LEM) configuration, which focuses on using low strength anaerobic digestion processes for treating raw domestic sewage, followed by nutrient removal processes (McCarty et al., 2011). The other is the Partition-Release-Recover (PRR) configuration, which focuses on a first stage of COD and nutrient accumulation in the solids, a second stage of release through the digestion process, and a final stage of digestate treatment (Verstraete et al., 2009).

In the literature there are numerous studies comparing different plant layouts and analysing the energy consumption of conventional WWTPs (Nowak, 2003; Gude, 2015, Tchobanoglous et al., 2014, Mininni et al., 2015), and fewer studies analysing advanced WWTPs (Garrido et al., 2013; Batstone et al., 2015; Khiewwijit et al., 2015), many of which use life cycle analysis (LCA) methods and decision support system (DSS) tools (Foley et al., 2010; Garrido-Baserba et al., 2014; Bisinella de Faria, et al., 2015; Castillo et al., 2016). Even so, virtually all these studies are based on operating cost analysis and/or are largely dependent on the quality of the data used and their specifications. However, one of the main problems found in these energy assessments is the limited information available to reproduce disturbances or unusual situations (Jenkins et al., 2014). It is for this reason that the best tool for overcoming all these obstacles is to conduct mass balances for COD, N and P for the whole plant (Spindler \& Vanrolleghem, 2012; Jenkins et al., 2014). The detailed analysis of each stream allows a better understanding of the process, identifying areas for improvement and opportunity for resource and energy recovery. Among existing approaches in the literature, the Plant-Wide Modelling (PWM) methodology proposed by Ceit-IK4 (Grau et al., 2007; Fernández-Arévalo et al., 2014; Lizarralde et al., 2015) constitutes a very suitable tool for rigorously and globally assessing the incorporation of new leading-edge technologies in conventional plant layouts (Fernández-Arévalo et al., 2015) or selecting the most appropriate operating strategies at existing full-scale facilities (Fernández-Arévalo et al., 2016).

The main objective of this paper is to conduct a comparative analysis of evolutionary WWTPs, from a techno-economic point of view, analysing in turn organic matter and nutrient energy use and recovery options. To do this, an upgraded plant and a newly designed plant have been analysed and compared against a conventional plant (based on the BSM2 configuration; Jeppsson et al., 2007). In the upgraded or retrofitted WWTP, thermal hydrolysis (TH) technology and a nitritation/Anammox process have been incorporated into the reference plant, and the new plant is a $\mathrm{C} / \mathrm{N} / \mathrm{P}$ decoupling WWTP, which is based on the PRR configuration proposed by Batstone et al., (2015). 


\section{MODELLING TOOL: Plant-Wide Model Library}

The Plant-Wide Modelling (PWM) methodology (Grau et al., 2007; Fernández-Arévalo et al., 2014; Lizarralde et al., 2015) allows the rigorous and systematic construction of compatible unit-process models (UPM) in order to describe the dynamic behaviour of different processes and technologies in the water and sludge lines in an integrated way. This PWM methodology is based on selecting, from a global list, the set of process transformations required to describe all unit-processes incorporated into each specific WWTP. Thus, the model will be constituted by a unique set of transformations and components vector that will allow the description of all relevant processes occurring in the plant. An accurate definition of the stoichiometry and the enthalpies of formation ensures the elemental mass, charge and energy continuity through the whole plant (FernándezArévalo et al., 2014). This methodology allows the straightforward construction of different plantwide models, which is especially suitable for the comparative assessment of any combination of existing technologies and configurations or those that are under development.

Following the guidelines proposed by Grau et al. (2007), Fernández-Arévalo et al. (2014) and Lizarralde et al. (2015) and with the goal of simplifying plant-wide models construction, this paper presents a new model library (Figure 1). The users can construct their own plant wide models by means the appropriate selection of the category, unit-process models and cost models depending on the case under study (Fernández-Arévalo et al., 2017).

\section{PLANT-WIDE MODEL LIBRARY}

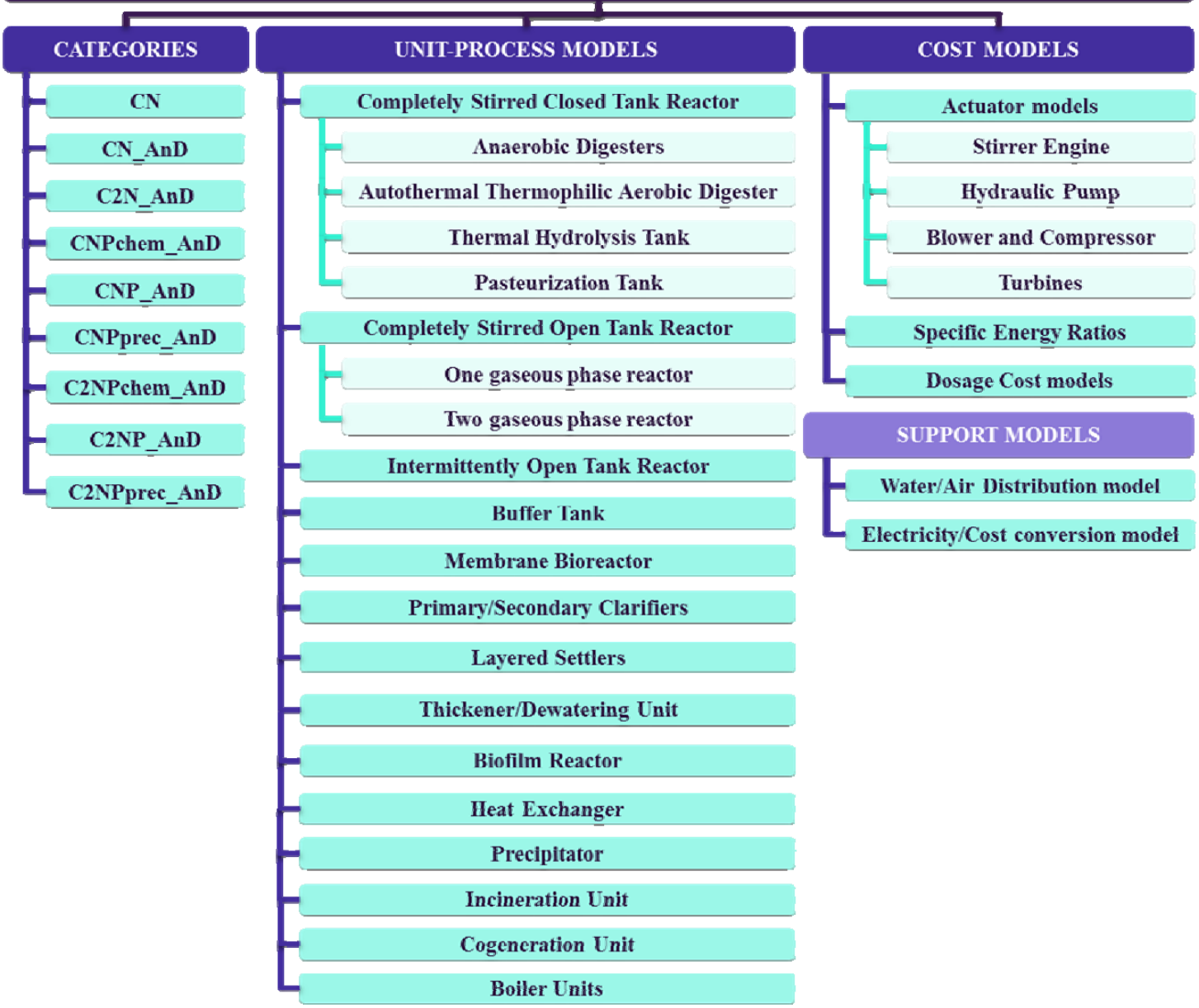

Figure 1. Schematic representation of the Ceit Plant-Wide Model library.

\subsection{Category selection}


Each category includes equations describing a set of biochemical, chemical and physico-chemical transformations. Depending on the complexity of the WWTP and the goals and scope of the modelling study users could select one category or another. The model categories have been developed combining conventional biological processes described in ASM (Henze et al., 2000) and ADM (Batstone et al., 2002) models with chemical and physico-chemical processes. All of them are represented by means of the definition of a stoichiometric matrix and kinetics vector (Grau et al., 2007; Lizarralde et al., 2015). The nomenclature used to define the categories is as follows: "C", "N" and "P" describe biological organic matter biodegradation, $\mathrm{N}$ biodegradation, and biological and chemical $\mathrm{P}$ removal, respectively, all of them in aerobic and anoxic conditions at low and high temperatures (TH reactions); "2N" specifies two-step N removal and Anammox reactions; "chem" denotes chemical P but not biological P removal; "prec" includes precipitation reactions; and finally, "AnD" describes anaerobic conditions at low and high temperatures (fermentation and digestion).

The organized structure that the methodology presents enables the straightforward development of categories, allowing the library to be continuously updated.

\subsection{Unit-process model selection}

The Ceit PWM library contains a set of unit-process models that describes the mass and energy transport in each unit. According to the features of novel technologies and processes analysed in advanced WWTPs, these models consider in most of the cases aqueous, gas and solid phases and mass and energy exchange among them (Fernández-Arévalo et al., 2014; Lizarralde et al., 2015).

\subsection{Cost model selection}

Lastly, the library includes a set of actuator models, specific energy ratios and dosage cost models in order to estimate in detail the costs of each element (see Table 1). All actuator models are developed based on engineering expressions instead of directly using cost curves or fixed values. The models are standardized, so they can be used interchangeably in any category.

Table 1. Description of cost models (Actuators, Specific Costs and Dosage Cost models)

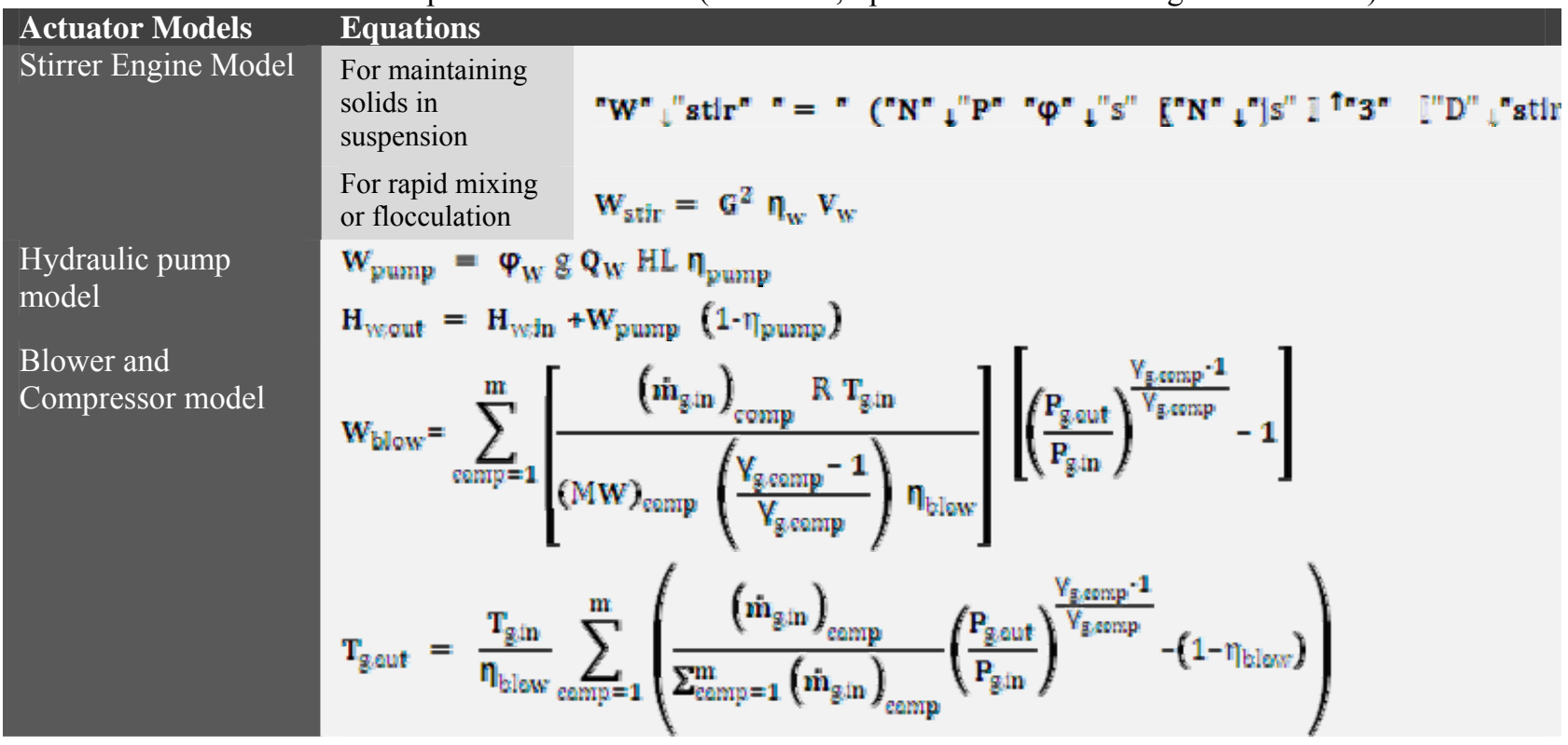




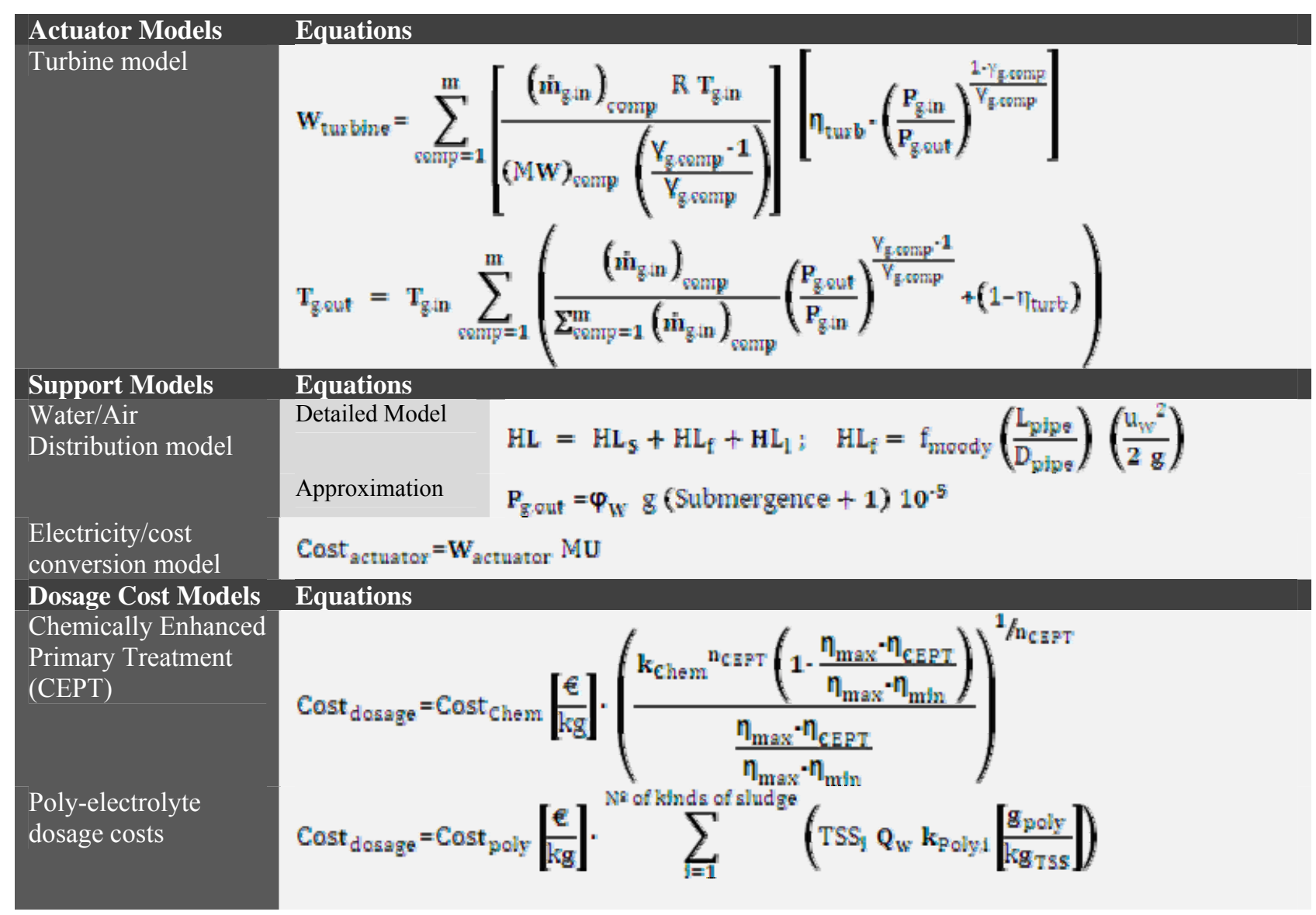

(Camp and Stein, 1943; CEDEX, 2004; Tchobanoglous et al., 2014; Tik et al., 2013; Weisbach, 1845; Zaher et al., 2009; Zweitering,

\section{DESCRIPTION OF THE SCENARIOS}

The comparative analysis of the three configurations selected (conventional WWTP, upgraded WWTP and C/N/P decoupling WWTP) has been based on PWM simulations. This section details the description of these plant layouts and the steps followed to build the model.

\subsection{Plant layouts definition}

\section{Conventional WWTP}

The reference WWTP considered in the study is a biological nutrient removal plant based on the Benchmark Simulation Model No. 2 (BSM2; Jeppsson et al., 2007). The plant layout (Figure 3) is constituted by a primary clarifier for the pre-treatment step, an AS process for $\mathrm{C}$ and $\mathrm{N}$ removal based on a Modified Ludzack-Ettinger configuration ( 2 anoxic and 3 aerobic tanks and a secondary clarifier), a dissolved air flotation (DAF) unit, an anaerobic digestion process and a dewatering step. A ferric chloride dosage is delivered to the output from the third aerobic tank for chemical $\mathrm{P}$ removal. Besides adding the chemical agents for $\mathrm{P}$ removal, ferric chloride can also be added to enhance the settling characteristics of the primary sludge for cases in which the production of primary sludge needs to be maximized. Finally, two other chemical additions are required in flotation and dewatering processes.

\section{Upgraded WWTP}

This second layout is based on the reference case (conventional WWTP), but with two advanced technologies being incorporated in the sludge line: a TH reactor and a nitritation/Anammox process for treating the rejected supernatants (Figure 4). 
The aim of the TH process is to maximise biogas production by increasing the biodegradability of the sludge. For this, pressurized steam must be fed to the reactor to maintain the chamber at $170{ }^{\circ} \mathrm{C}$ (Fernández-Polanco et al., 2008). In this scenario, part of the biogas produced in the anaerobic digestion was diverted to a boiler to cause combustion and produce the required steam. The amount of biogas required for the $\mathrm{TH}$ and consequently, the benefits in electricity generation will depend on the incoming sludge temperature and concentration that will be crucial for the profitability of the process. The increase in sludge biodegradability also involves an extra release of ammonium $\left(\mathrm{NH}_{\mathrm{X}^{-}}\right.$ $\mathrm{N}$ ), which must be treated in situ. To remove this surplus of $\mathrm{N}$ and the $\mathrm{NH}_{\mathrm{X}}-\mathrm{N}$ released in anaerobic digestion, a nitritation/Anammox process is an interesting approach. In the Anammox process, ammonium is oxidized with the nitrites formed in the previous nitritation process, without oxygen and COD consumption, raising the stoichiometric aeration cost savings up to $63 \%$ (Volcke et al., 2006).

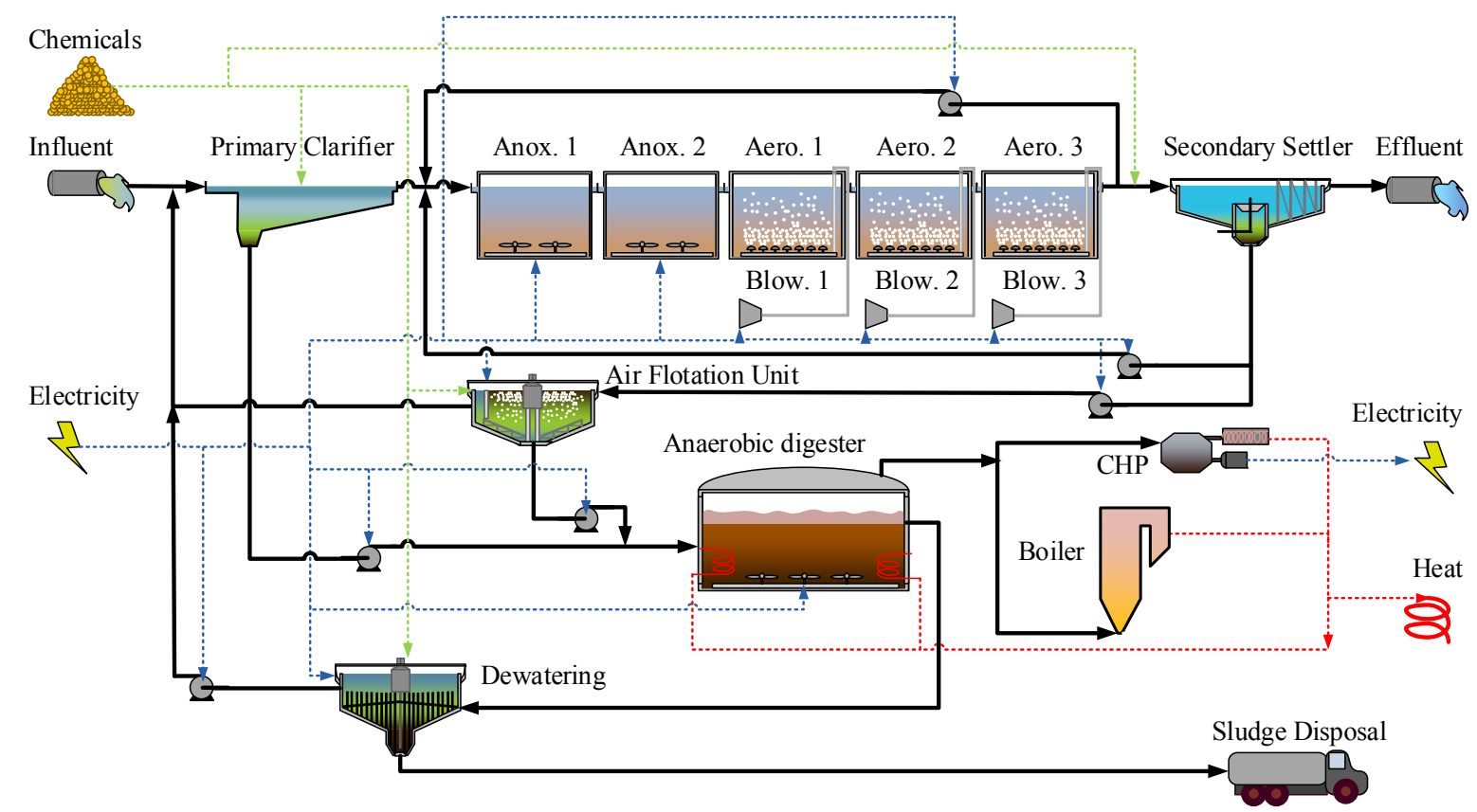

Figure 3. Conventional wastewater treatment plant (based on BSM2 layout) 


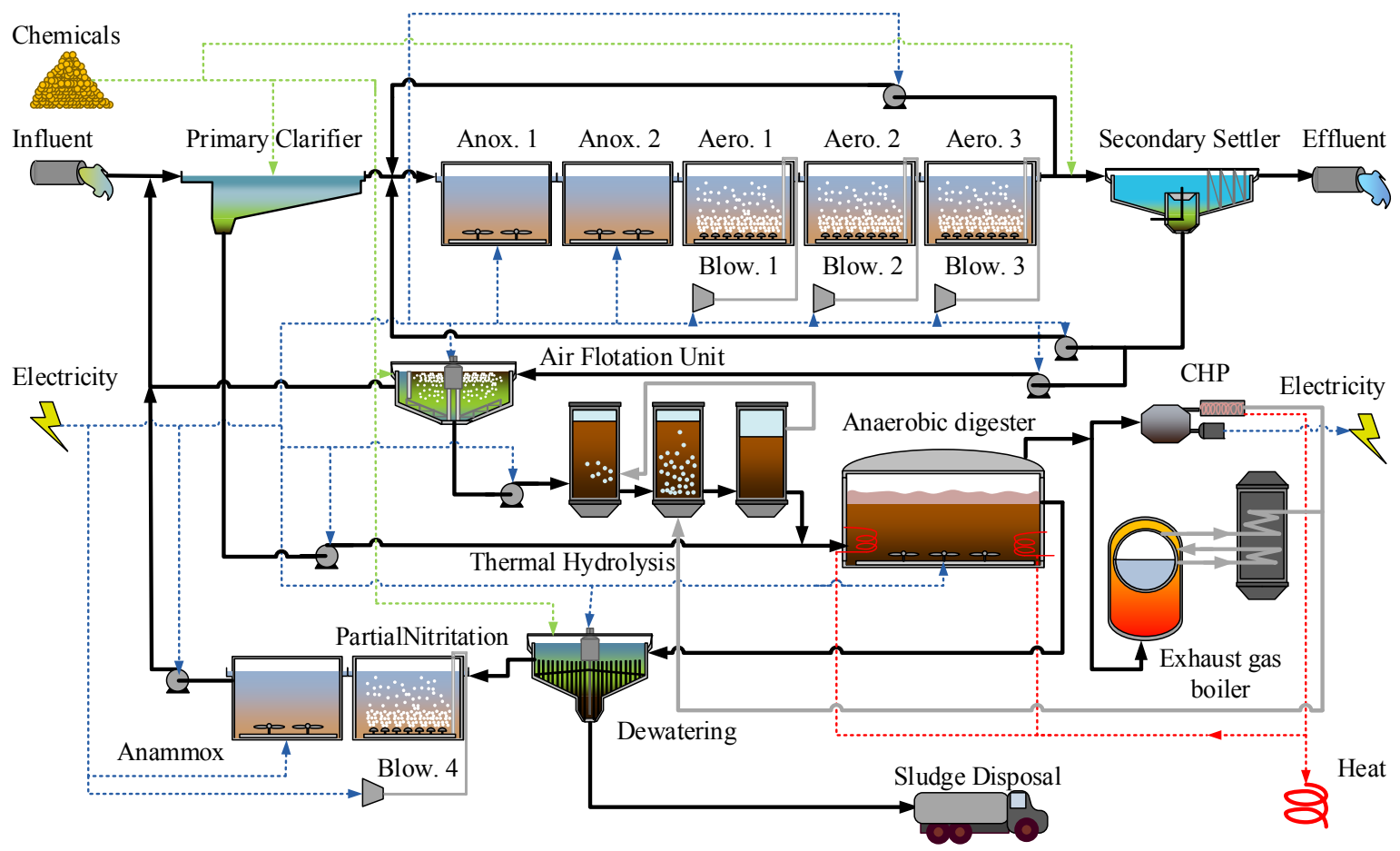

Figure 4. Upgraded wastewater treatment plant

\section{New WRRF concept: C/N/P decoupling WWTP}

The partition-release-recover (PRR) concept proposed by Batstone et al., (2015) was used as an example of new WRRF concept. This configuration completely decouples COD and nutrient treatments in order to seek greater process performance. For this, the water line reactors are operated at very short sludge retention time or SRT (2-4 days, depending on the temperature) to consume only the strictly necessary $\mathrm{N}$ for the growth of the microorganisms. The configuration (Figure 5) consists of a Phoredox (A/O) process for the biological soluble COD and orthophosphates (ortho-P) accumulation in the solids (heterotrophic organisms, polyphosphate (polyP) accumulating organisms (PAO), polyhydroxyalkanoates (PHA) and polyP), a thermal hydrolysis technology to increase the biodegradability and dewaterability of sludge, an anaerobic sludge digestion process for the COD removal and $\mathrm{P}$ and $\mathrm{N}$ release, a crystalliser for $\mathrm{P}$ precipitation as struvite $\left(\mathrm{MgNH}_{4} \mathrm{PO}_{4} \cdot 6 \mathrm{H}_{2} \mathrm{O}\right)$, and a partial nitritation/Anammox process in the mainstream and side stream to treat the $\mathrm{N}$. 


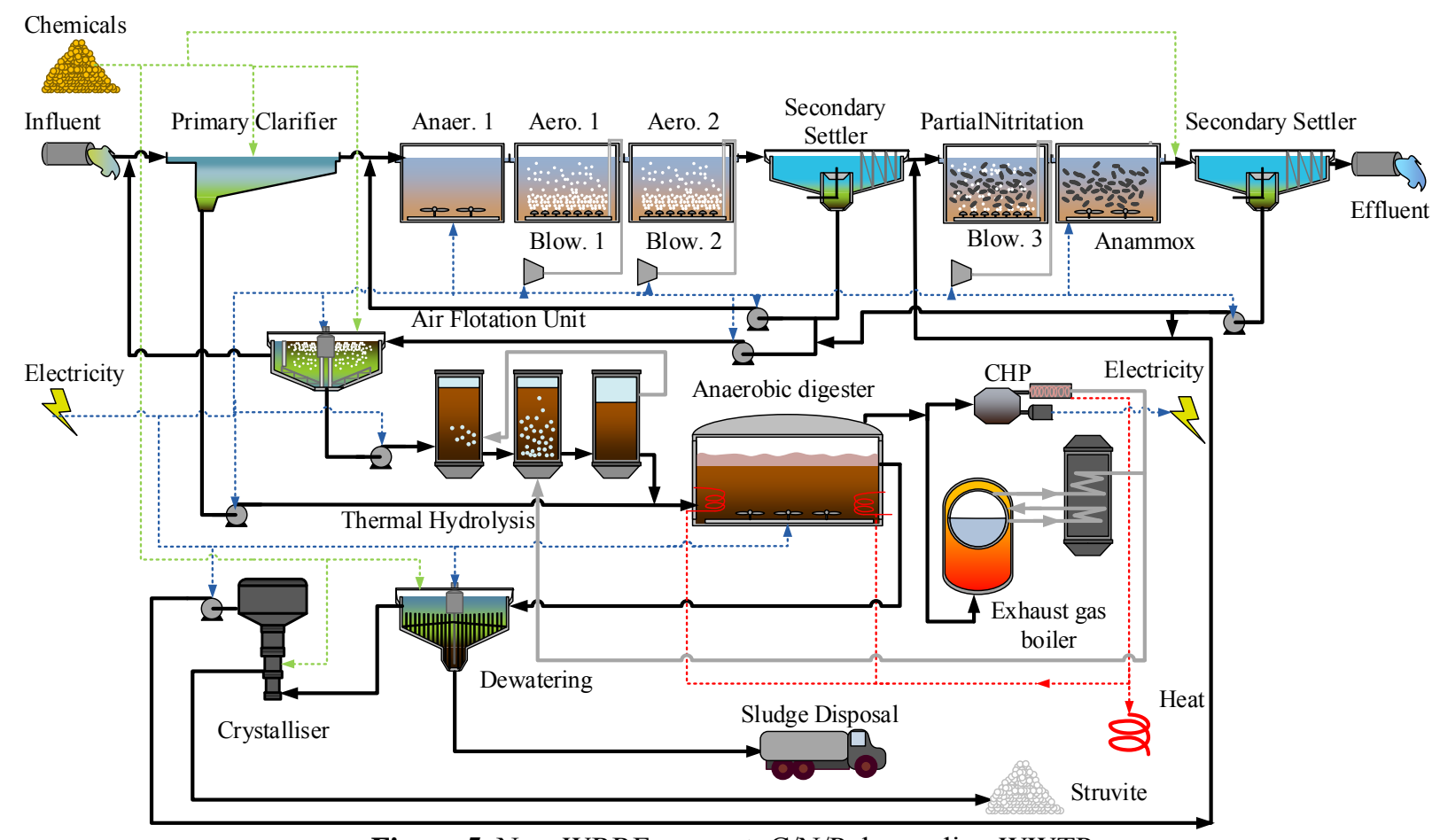

Figure 5. New WRRF concept: C/N/P decoupling WWTP.

\subsection{Plant-Wide Model construction}

Based on the Ceit PWM library, the models describing the three scenarios abovementioned where constructed and implemented in the WEST simulation platform (www.mikebydhi.com) following the steps describe below.

\subsubsection{Category selection and influent characterization}

Given the characteristics of the three plant layouts, the CNPchem_AnD, the C2NPchem_AnD and the C2NPprec AnD categories from the Ceit PWM library were selected to reproduce the behaviour of all plants. The biochemical reactions considered in the model were the ones that are necessary to describe biological organic matter, $\mathrm{P}$ and two-step $\mathrm{N}$ removal under different environmental conditions (aerobic, anoxic and anaerobic). The chemical transformations considered in the model were the weak acid-base and complex ion-pairing equilibrium reactions between volatile fatty acids (VFAs), inorganic carbon, N, P, calcium, magnesium and potassium. Finally, two types of physico-chemical transformations were considered: (1) liquid-gas transfer, regulated by gaseous partial pressure according to Henry's law of dissolution, and (2) the precipitationredissolution equilibrium.

Influent wastewater was simulated using the average flow-weighted influent concentrations calculated for one year of influent defined in BSM2 (Gernaey et al., 2014), with some minor modifications and additions. The SCOD/TCOD ratio was increased from 0.14 to 0.44 to allow the complete denitrification and fermentation processes. The VFA concentration was set on $15 \%$ of the soluble and colloidal COD (Henze et al., 2008). The colloidal fraction of the slowly biodegradable matter remained at $25 \%$, the TKN/TP ratio at 5 and the VSS/TSS at 0.76 .

\subsubsection{Unit-process and actuator model selection}

In each configuration, the units were selected to describe the detailed layouts in the previous section (Completely stirred open and closed tank reactors, primary and secondary clarifiers, thickener and dewatering units, biofilm reactors, CHP units, boilers, heat exchangers and precipitation units). To 
describe the major costs of the system the following models were selected: blowers, pumps, stirrer engines, gas and water distribution systems, specific energy ratios, dosage costs and electricity/cost conversion models. The dehydration process is described from specific energy ratios and dosage costs, and in the case of flotation the process is described by specific energy ratios and pumping, aeration and dosage costs. All these cost models were calibrated from standard engineering values.

\section{SIMULATION ANALYSIS: ENERGY AND NUTRIENT MANAGEMENT EXPLORATION}

Once the models for the three scenarios proposed were constructed, (steady state) simulations were carried out to analyse the potential use of the energy contained in the organic matter and nutrients and/or its recovery. Furthermore, a cost analysis of these plants for different influent $\mathrm{C} / \mathrm{N} / \mathrm{P}$ ratios was carried out. To avoid possible interferences from other factors that affect plant operation (plant oversizing, unit-process efficiencies, environmental factors, etc.), reactor volumes and recycle flows have been optimized for each plant layout and for each influent in order to fulfil a fixed effluent quality of $10 \mathrm{gN} \mathrm{m}^{-3}, 1 \mathrm{gP} \mathrm{m}^{-3}, 125 \mathrm{gCOD} \mathrm{m}^{-3}$ and $35 \mathrm{gSS} \mathrm{m}^{-3}$, accordingly to the European Directive 91/271/EEC.

\subsection{General considerations about the potential use of the energy contained in COD and nutrient and/or its recovery options in WWT processes}

In analysing the different conventional options of getting energy from COD removal, the most effective and typical way is to transform the organic matter into $\mathrm{CH}_{4}$ (the $\Delta \mathrm{h}_{\mathrm{r}}{ }^{\circ} \mathrm{CH} 4$ is $13.91 \mathrm{~kJ} \mathrm{gCOD}^{-}$ ${ }^{1}$ or $890 \mathrm{~kJ} \mathrm{~mol}^{-1}$ ) and use its combustion to produce thermal and electric energy. The anaerobic COD biodegradation presents three advantages against aerobic or anoxic oxidation in AS: (1) the heat of reaction is higher, 11.86-13.37 $\mathrm{kJ} \mathrm{gCOD}_{\mathrm{rem}}{ }^{-1}$ against $4.07 \mathrm{~kJ} \mathrm{gCOD}_{\mathrm{rem}^{-1}}{ }^{-1}-27 \mathrm{~kJ}_{\mathrm{gCOD}}{ }^{-1}$ for aerobic and $3.52 \mathrm{~kJ} \mathrm{gCOD}_{\mathrm{rem}^{-1}}-4.74 \mathrm{~kJ} \mathrm{gCOD}_{\mathrm{rem}}{ }^{-1}$ for anoxic biodegradation (calculated from Table 2), (2) the energy recovery from biogas combustion is more effective because of the heat dissipated when oxidation occurs in the aqueous phase, and (3) aeration costs are reduced. Thus, the clearest alternative to maximize the recovery or reuse of the COD energy potential is to minimize the COD oxidation in AS processes. This can be obtained by producing more primary sludge and working at lower SRT in the secondary biological treatment.

Table 2 - Specific heat yields (or energy content) estimated with the PWM methodology

\begin{tabular}{|c|c|c|c|c|c|c|c|}
\hline Transformations & $\mathrm{S}_{\mathrm{SU}}$ & $\mathrm{S}_{\mathrm{AA}}$ & $\mathrm{S}_{\mathrm{FA}}$ & $\mathrm{S}_{\mathrm{HVA}}$ & $\mathrm{S}_{\mathrm{HBU}}$ & $\mathrm{S}_{\mathrm{HPRO}}$ & $\mathrm{S}_{\mathrm{HAC}}$ \\
\hline Aerobic COD removal heat ( $\mathrm{kJ}$ gCOD rem. $^{-1}$ ) & -5.27 & -4.41 & -4.07 & -4.14 & -4.17 & -4.19 & -4.32 \\
\hline Aerobic COD removal heat $\left(\mathrm{kJ} \mathrm{mol}_{\mathrm{rem} .}{ }^{-1}\right)$ & -1011 & -2997 & -2997 & -862 & -667 & -469 & -276 \\
\hline Anoxic COD removal heat ( $\mathrm{kJ}$ gCOD rem. $\left.^{-1}\right)$ & -4.74 & -3.89 & -3.55 & -3.52 & -3.64 & -3.67 & -3.79 \\
\hline Anoxic COD removal heat $\left(\mathrm{kJ} \mathrm{mol}_{\left.\mathrm{rem}^{-1}\right)}\right.$ & -910 & -520 & -2610 & -753 & -583 & -410 & -243 \\
\hline Anaerobic COD removal heat $\left(\mathrm{kJ} \text { gCOD } \text { rem. }^{-1}\right)^{\ddagger}$ & -1.01 & -0.17 & 0.14 & 0.08 & 0.04 & 0.00 & -0.15 \\
\hline Anaerobic COD removal heat $\left(\mathrm{kJ} \mathrm{mol}_{\mathrm{rem}^{-1}}\right)^{\ddagger}$ & -195 & -22 & 101 & 17 & 9 & 1 & -25 \\
\hline
\end{tabular}

Although, as it's been abovementioned, the energy recover from compounds is more efficient when they are in a gaseous phase. In the case of the ammonia, its solubility in water is very high, necessitating stripping methods for transferring from water into gas phase. This, added to the fact that ammonia requires a catalyst for its oxidation in gas phase (Jones et al., 1999), makes this process economically unfeasible. Moreover, the nitrogen recovery techniques (ion exchange methods or stripping processes) consume more energy than removal processes, with the exception of struvite recovery technologies. Consequently, from an economic perspective, the destruction of nitrogen compounds appears the most logical route (Matassa et al., 2016) and low-energy alternatives can be proposed, such as the use of Anammox bacteria, anaerobic phototropic bacteria or high-rate algae (Batstone and Virdis, 2014). Comparing the $\mathrm{N}$ oxidation reactions in the aqueous 
phase, the Anammox reaction is the one that release more energy to the medium $\left(23.32 \mathrm{~kJ} \mathrm{gN}_{\text {rem }}^{-1}\right)$,

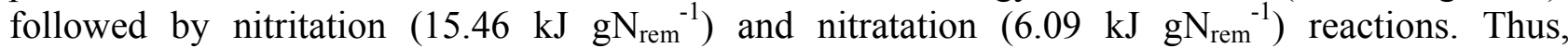
Nitritation/Anammox reactions maximize the energy utilization of the $\mathrm{N}$ and minimize oxygen consumption in the process that leads to a reduction in the aeration costs.

Finally, the scarcity of natural phosphorus resources converts the recovery of $\mathrm{P}$ into the first alternative for use. Currently, $\mathrm{P}$ recovery methods from MWW include the agricultural use of sludge, production of struvite, particularly in enhanced biological P removal (EBPR) plants, and the recovery of $\mathrm{P}$ from ash (Wilfert et al., 2015). On the other hand, phosphorus removal itself, using biological or chemical processes does not exert any effect on energy balances.

\subsection{Analysis of the energy use of a conventional wastewater treatment plant}

To analyse the degree of utilization of thermal energy content (energy associated with the fluid temperature) and mass energy content (energy associated with the composition of water), a global plant-wide simulation of a conventional plant was carried out under steady-state conditions for a critical temperature of $13^{\circ} \mathrm{C}$.

Based on the mass and energy fluxes proposed by Pagilla et al. (2004), Figure 6 shows the maximum energy potential of the wastewater in each point of the plant. The top of the figure shows the total thermal energy or enthalpy (not exergy) associated with temperature, while the bottom part reflects the maximum energy potential of the constituents in the water, that is the energy released upon oxidation of all water components to $\mathrm{CO}_{2}, \mathrm{H}_{2} \mathrm{O}, \mathrm{NO}_{3}$ and $\mathrm{H}_{3} \mathrm{PO}_{4}$.

As shown in Figure 6, the biological heat and the solar and atmospheric radiations increased the temperature of the aqueous phase by $0.5-2$ degrees $\left(1.5^{\circ} \mathrm{C}\right.$ for this case study) and the thermal energy output of the plant by $10 \%$ (energy loss through the effluent). Heat recovery technologies (Wanner et al., 2005; Corbala-Robles et al., 2016) could be an appropriate solution for taking advantage of this thermal energy. However, the obtained heat $\left(55-75^{\circ} \mathrm{C}\right.$, Alekseiko et al., 2014) is a very low exergy stream and its application is limited to use in the plant itself or in WWTPs located near a residential area or near hot water demanding areas (IWA Resource Recovery Cluster, 2015). In spite of this, its high coefficient of performance (COP or the ratio of heating provided to work required), which is between 1.77 and 10.63, makes it a promising technology (Hepbasli et al., 2014).

Simulation results show that a considerable fraction of the mass energy content is released to the atmosphere or aqueous phase as biological heat (35-40\%) due to the transformations that occurred in the system. Among these transformations, nitrification reactions brought more specific energy to the system $\left(21.61 \mathrm{~kJ} \mathrm{gN}_{\mathrm{rem}}{ }^{-1}\right)$, followed by the COD oxidation reactions (Table 1). Around $30 \%$ of the mass energy content is converted into biogas and goes to the CHP unit. In this specific case, for a mass flow of $7.7 \mathrm{t}_{\mathrm{COD}} \mathrm{d}^{-1}\left(42.6 \mathrm{~kg}_{\mathrm{COD}} \mathrm{m}^{-3}\right)$ entering to the anaerobic digester and a temperature of $13^{\circ} \mathrm{C}$, it is not possible to maintain the mesophilic temperature, and $3-5 \%$ of COD is addressed to the boiler, reducing the electrical energy production. Consequently, at this particular case, only $10 \%$ of the mass energy content in MWW is converted into electricity, losing the remaining energy by heat dissipation (4\%), through the effluent ( $8 \%$ mass content and 37\% thermal content), through the sludge $(26 \%)$, and digester heating (15\%). From the analysis of Figure 6, it can be said that in a conventional plant, most of the influent energy potential is lost as heat (digester heating and oxidation reactions).

Points highlighted in sections 4.1 and 4.2, shows that a rigorous energy and mass flow analysis is crucial for assessing the potentiality of the plant in terms of (1) energy use and recovery and (2) 
valuable recovered products production. According to this, section 4.3 will show as an example, a simulation-based analysis of the three plant layouts presented in section 3 and for different operating scenarios.

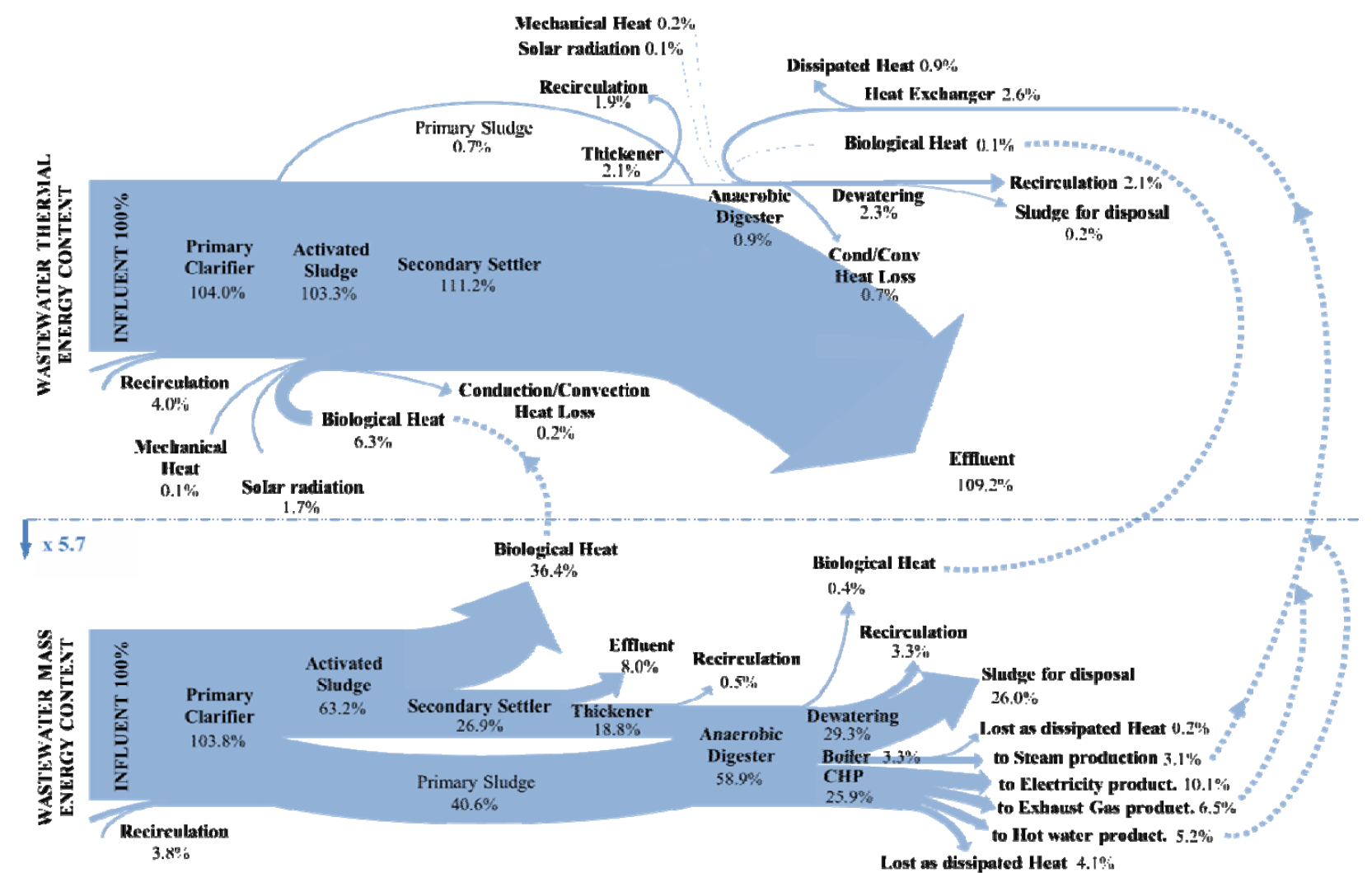

Figure 6. Simulation of the wastewater mass and energy content distribution throughout the conventional WWTP.

\subsection{Comparative analysis of COD and nutrient (N/P) flux distributions in a conventional, upgraded and $\mathrm{C} / \mathrm{N} / \mathrm{P}$ decoupling WWTP}

In order to analyse the potential of the wastewater mass energy content, a set of PWM simulations has been carried out. To that end, the distribution of COD, N and P flows throughout the plants was assessed in the traditional, upgraded and $\mathrm{C} / \mathrm{N} / \mathrm{P}$ decoupling plant under stationary conditions for a temperature of $18^{\circ} \mathrm{C}$. At this temperature all the biogas is conducted to $\mathrm{CHP}$ in the three casestudies, which simplifies the comparison.

\section{Conventional WWTP}

As discussed in the previous section, the way to use the maximum energy content of COD is to convert this organic matter into $\mathrm{CH}_{4}$. Although in the conventional plant analysis (Figures 7, 8 and 9), only $29 \%$ of the influent COD is transformed into biogas, this value turns into $43 \%$ if the influent non-biodegradable organic matter $\left(20 \%\right.$ of the COD $\left.\left(\mathrm{S}_{\mathrm{I}}, \mathrm{X}_{\mathrm{I}}\right)\right)$ and the non-biodegradable fraction produced in the plant $\left(12 \%\left(\mathrm{~S}_{\mathrm{P}}, \mathrm{X}_{\mathrm{P}}\right)\right)$ are not considered. Given this, it's clear that maximizing the biogas generation by (1) producing more primary and secondary sludge and (2) transforming part of the non-biodegradable organic matter into biodegradable, for example, by using mechanical (ultrasound treatments, high-pressure homogenisation), thermal (thermal hydrolysis), chemical (ozonation, Alkali treatments) or biological alternatives (Pérez-Elvira et al., 2006), could improve significantly the organic matter energetic potential.

Regarding the total $\mathrm{N}(\mathrm{TN})$ balance of this study, $58 \%$ of the $\mathrm{N}$ is denitrified, $17 \%$ and $25 \%$ are extracted from the effluent and dewatered sludge, respectively, and $25 \%$ of the $\mathrm{N}$ is recirculated 
back to the water line as $\mathrm{NH}_{\mathrm{x}}-\mathrm{N}$. The $\mathrm{N}$ percentage extracted from this dewatered sludge is not a fixed value and it is closely related to the degree of volatile solids (VS) removed in the anaerobic digestion process. The volatile solids removal efficiency is approximately proportional to the degree of $\mathrm{NH}_{\mathrm{X}}-\mathrm{N}$ released. In this case, for a VS removal of $51 \%$, a formation of $51 \% \mathrm{NH}_{\mathrm{x}}-\mathrm{N}$ with respect to the TN feed to the digester has been observed.

Finally, as previously mentioned, $\mathrm{P}$ is a component that is extracted from the plant only within the effluent and sludge. Thus, the flow of total P (TP) in the dewatered sludge $(80 \%$ in this case) depends on the P concentration in the influent and effluent. For a high P load influent $\left(25 \mathrm{gP} / \mathrm{m}^{3}\right.$, Henze et al, 2008) the percentage of TP extracted as solids can be $92-96 \%$, while for a low P load influent $\left(6 \mathrm{gP} / \mathrm{m}^{3}\right.$, Henze et al, 2008) it can be about $60-80 \%$, which is in accordance with our calculations (Figure 9).

\section{Upgraded WWTP}

In this case, incorporating the thermal hydrolysis technology, allows the secondary sludge biodegradability to be increased (by $40 \%$ in this particular study), thus converting the nonbiodegradable matter, $\mathrm{X}_{\mathrm{P}}$, into biodegradable matter $\left(\mathrm{X}_{\mathrm{CH}}, \mathrm{X}_{\mathrm{PR}}, \mathrm{X}_{\mathrm{LI}}\right)$ and consequently increasing biogas production (by $27 \%$ in this particular case study, and by $40 \%$ when only secondary sludge is digested). This production depends mainly on the proportions of primary and secondary sludge fed to the digester. The extra amount of COD transformed into methane is approximately the same as the amount by which COD decreased in the dewatered sludge, in this case the extracted COD was reduced by $19 \%$ and the sludge produced by $12 \%$ (as a function of the VSS/TSS ratio). The degradation of this new fraction of biodegradable organic matter (part of $\mathrm{X}_{\mathrm{P}}$ ) will release $25 \%$ more $\mathrm{NH}_{\mathrm{X}}-\mathrm{N}$ and $23 \%$ more ortho-P in the digested sludge, thereby decreasing the content of TN and TP in dewatered sludge and increasing the content of $\mathrm{NH}_{\mathrm{X}}-\mathrm{N}$ and ortho-P slightly (by $25 \%$ and $23 \%$, respectively). Thus, the resulting reject water will contribute to an increase in the $\mathrm{N}$ load to be treated in the AS process by up to $30 \%$. This can be a problem if the biological plant does not have sufficient capacity to treat this additional nitrogen load. Thus, before incorporating any technology, it is useful to analyse its repercussions and viability in the plant as a whole.

With the inclusion of the nitritation/Anammox process the total $\mathrm{N}$ flux in the reject water stream was reduced by $70 \%$ and the $\mathrm{NH}_{\mathrm{X}}-\mathrm{N}$ flux by $92 \%$, decreasing in turn the $\mathrm{NH}_{\mathrm{X}}-\mathrm{N}$ to be treated in the AS process by $28 \%$. By using either energy-efficient technologies (nitritation/Anammox) or conventional $\mathrm{N}$ removal technologies (denitrification-nitrification processes), the $\mathrm{N}$ gas released to the atmosphere is similar in both cases $(58 \%)$. In this plant layout, due to the pre-treatment incorporated $(\mathrm{TH})$, the plant has to treat more $\mathrm{NH}_{\mathrm{X}}-\mathrm{N}$ or more biodegradable nitrogen. This results in increased amounts of nitrogen lost by stripping (64\%).

The release of these extra nutrients can increase the probability of uncontrolled precipitation of salts (struvite, calcium ortho-P, etc.), if the concentration of ions $\left(\mathrm{Mg}^{++}, \mathrm{Ca}^{++}\right.$, etc.) is considerable and if the process conditions favour them. Thus, although the plant does not have biological P removal, the $\mathrm{P}$ released in the digestion can be enough to generate uncontrolled precipitation problems. 

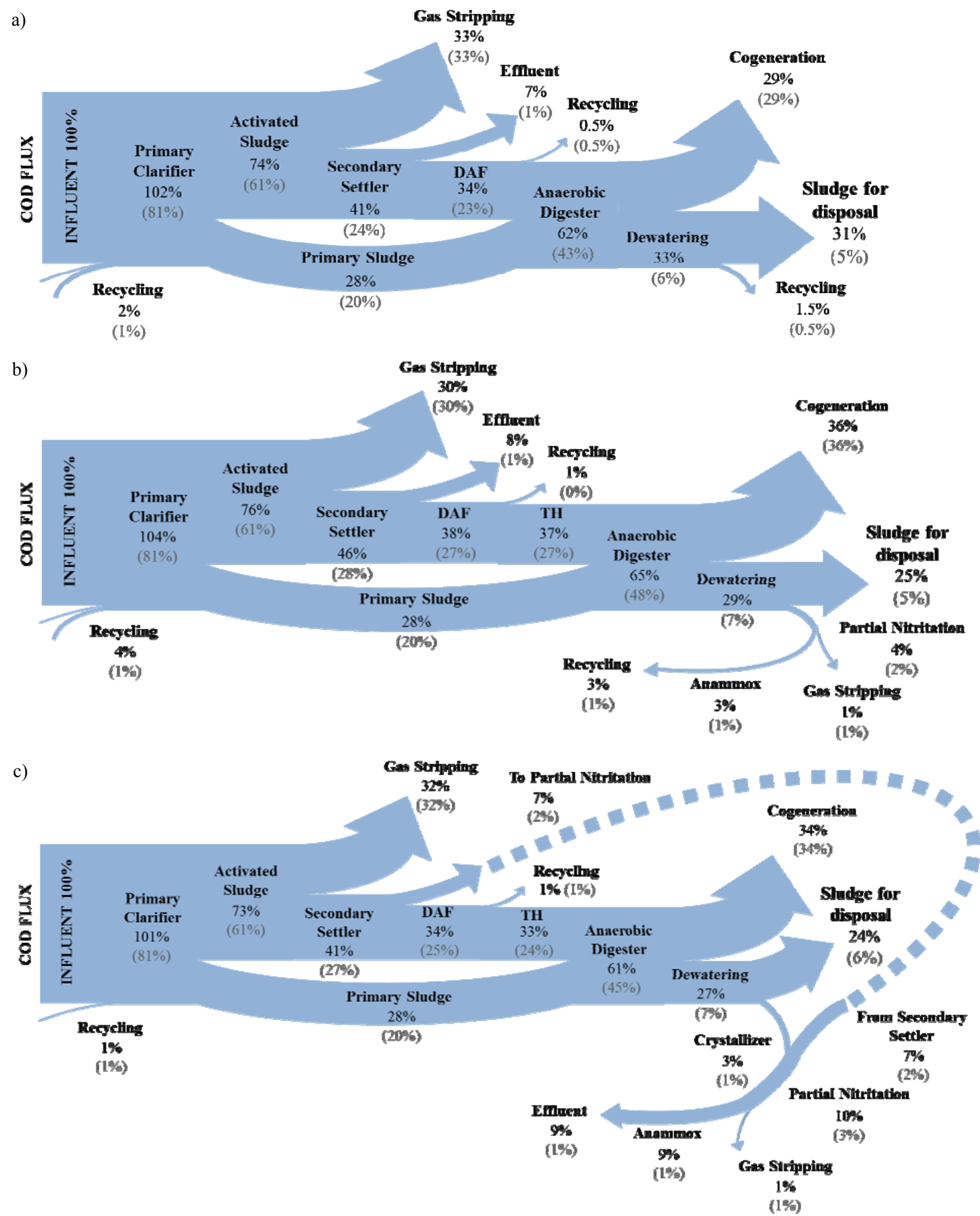

Figure 7. Simulation of the total COD and (biodegradable COD) flux distributions throughout: (a) a conventional WWTP, (b) an upgraded WWTP, and (c) a C/N/P decoupling WWTP 

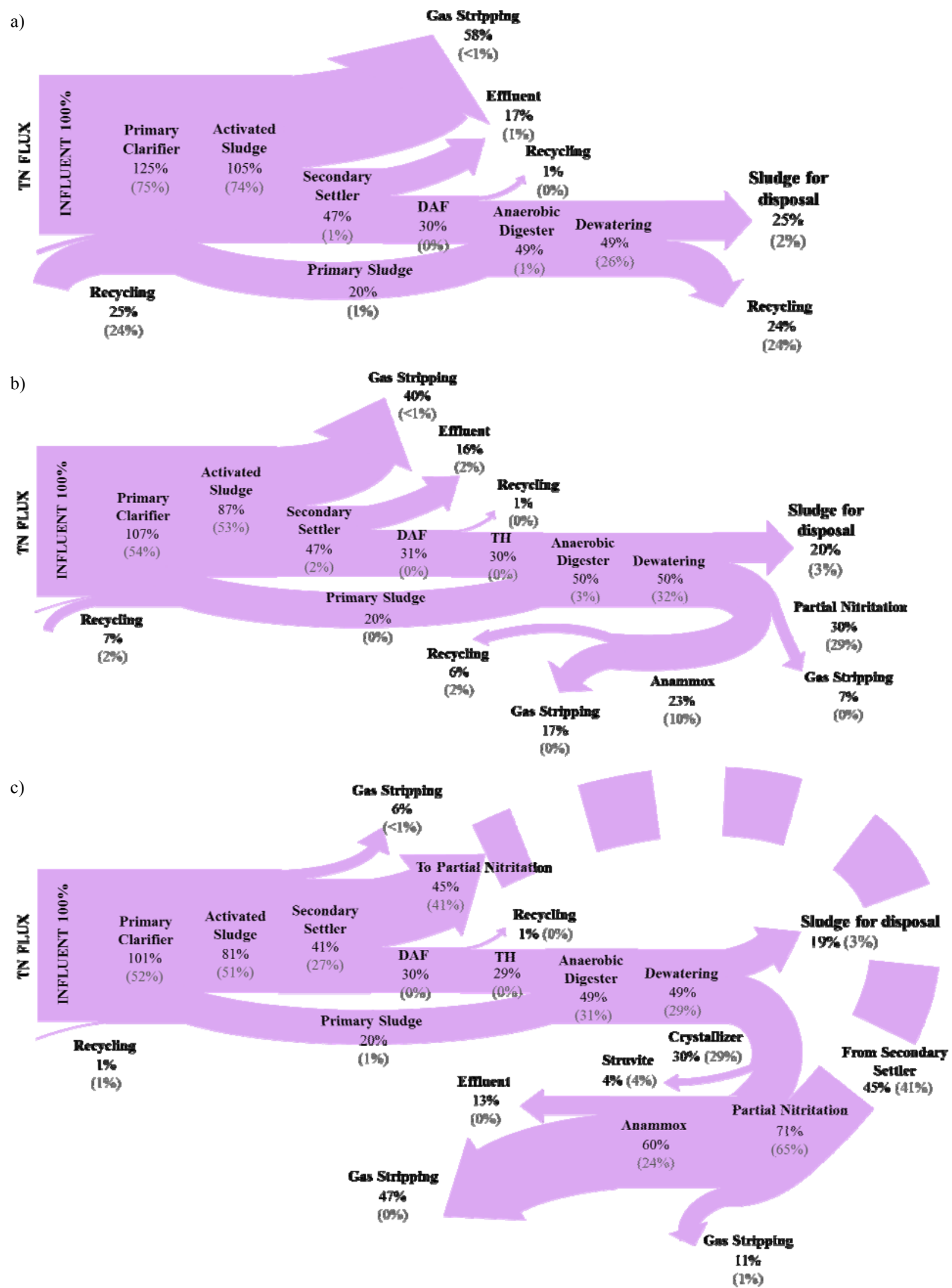

Figure 8. Simulation of the TN and $\left(\mathrm{NH}_{\mathrm{X}} \mathrm{-N}\right)$ flux distributions throughout: (a) a conventional WWTP, (b) an upgraded WWTP, and (c) a C/N/P decoupling WWTP 

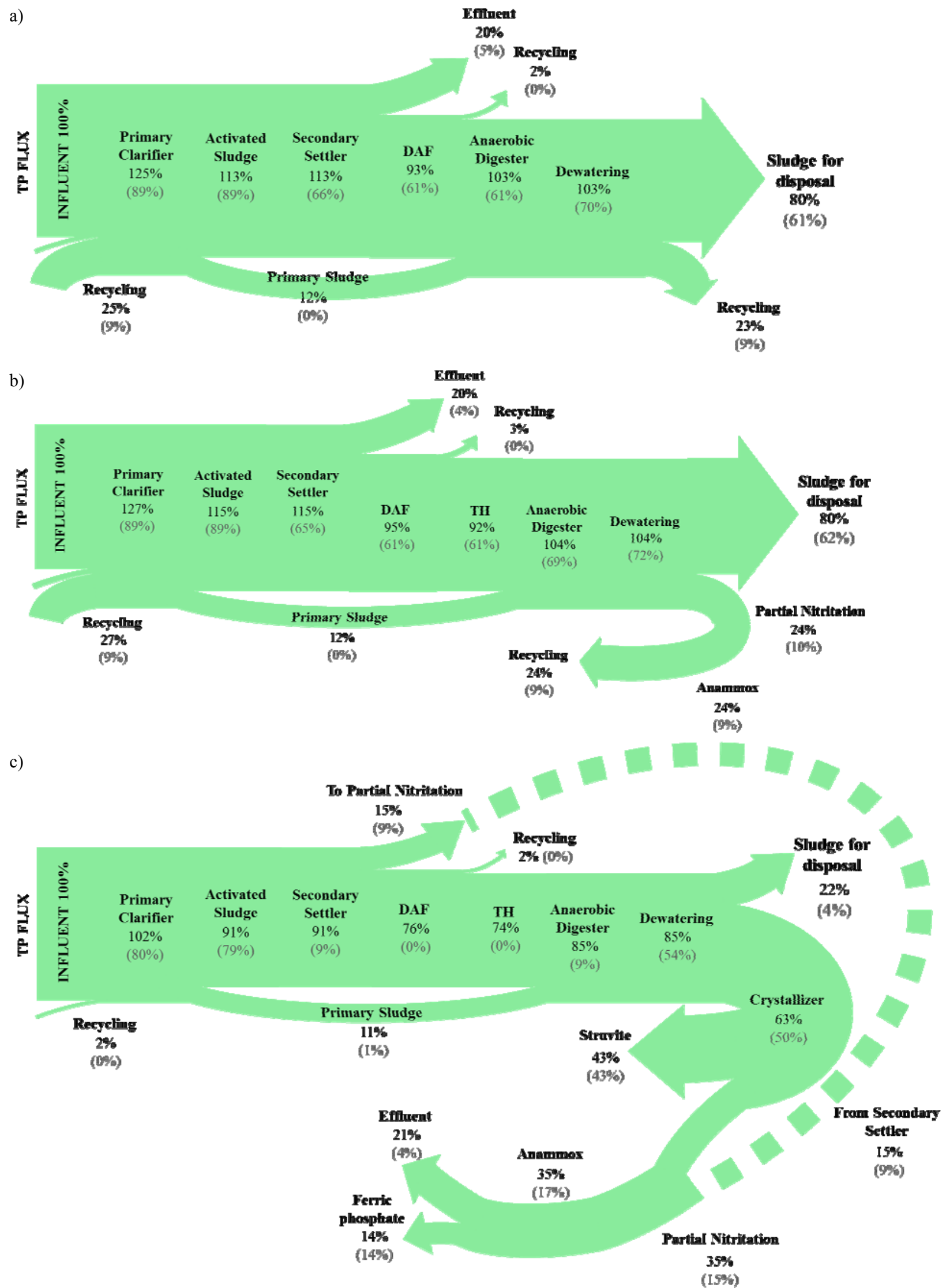

Figure 9. Simulation of the TP and ortho-P flux distributions throughout: (a) a conventional WWTP, (b) an upgraded WWTP, and (c) a C/N/P decoupling WWTP 
This new treatment concept consists of treating each compound (organic matter, $\mathrm{N}$ and $\mathrm{P}$ ) in the most efficient way possible, promoting recovery and maximizing energy use: organic matter is valorised as biogas, the $\mathrm{P}$ is recovered as struvite and the $\mathrm{N}$ is treated with energy-efficient technologies.

By working at low solids retention time of 3 days (to avoid nitrification and an excessive accumulation of inerts), the production of non-biodegradable organic matter, due to decay processes, is lower (12\% lower than in the conventional configuration), but the same amount of $\mathrm{CO}_{2}$ is produced due to acidogenesis, PAO bacteria growth and polyP storage reactions. Therefore, this plant layout should not be used with the goal of increasing biogas production. Once again, to increase the biodegradability of the sludge, a thermal hydrolysis unit was introduced to the global plant configuration, obtaining in this case a $21 \%$ increase in biogas production. If the objective had been to only maximize the production of biogas, without paying attention to the removal and recovery of $\mathrm{P}$, the configuration could have been modified to a high load fully aerated configuration (without anaerobic reactors to accumulate the $\mathrm{P}$ ), and in that case, biogas production would have increased up to $40 \%$ (about $20 \%-25 \%$ due to the thermal hydrolysis and another $15 \%-20 \%$ due to the high-rate process).

In the anaerobic digestion process the ortho-P accumulated in PAO bacteria is released, along with the ortho-P previously released into the TH process. Unlike a configuration without biological $\mathrm{P}$ removal, in which the percentage of ortho-P at the outlet of digestion is $9-11 \%$ of the TP influent, in a configuration with $\mathrm{P}$ accumulation this percentage can increase up to 54\%. Thus, the dewatered sludge will contain $72 \%$ less $\mathrm{P}$, but a greater amount of ortho-P. The recovery of this ortho-P can be accomplished by recovery in crystallization units. The percentage of $\mathrm{P}$ recovered depend on factors such as the influent $\mathrm{P}$ and ions (uncontrolled precipitation problems) composition, the required effluent quality, the $\mathrm{P}$ accumulation efficiency of AS processes, the need for chemical agents in the water line $\left(\mathrm{FeCl}_{3}\right)$ and the efficiency of VS removal in digestion, among other things, making it possible to recover $43 \%$ of $\mathrm{P}$ as struvite.

Finally, a large proportion of the influent N (79\%) will be treated with efficient technologies, since $\mathrm{N}$ fluxes recovered as struvite and released by stripping into the AS process were minimal (in this particular case by $4 \%$ and $6 \%$, respectively).

The mass flow analysis allows tracking of components throughout the plant. In a WRRF concept, these components are associated with a source of valuable products and bioenergy. So indirectly, it is an analysis of the plant recovery potential, and consequently an analysis of the plant efficiency. In this frame, the aim of the last section was the estimation of the treatment costs associated with these streams and the quantification of the energy produced or recovered.

\subsection{Analysis of the costs distributions in a conventional, upgraded and $C / N / P$ decoupling WWTP for different influent $\mathrm{COD} / \mathrm{N} / \mathrm{P}$ ratios}

The most influential factors on WWTP operating costs are the plant layout and the composition of the MWW influent. In order to analyse the effect of these factors, a global economic analysis of each plant layout was carried out for different influent COD/TN ratios (Table 3), under stationary conditions and for a temperature of $18^{\circ} \mathrm{C}$. The ratio TN/TP has been maintained constant. Reactor volumes and operational set-points have been optimized for each particular plant layout and for each influent composition.

Table $3-\mathrm{C} / \mathrm{N}$ ratios considered for the influent characterization 


$\begin{array}{llccc} & & 444 \mathrm{gCOD} \mathrm{m}^{-3} & 592 \mathrm{gCOD} \mathrm{m} \mathrm{m}^{-3} & 740 \mathrm{gCOD} \mathrm{m} \mathrm{m}^{-3} \\ \text { Low TN (LN) } & 43 \mathrm{gN} \mathrm{m}^{-3} & \mathrm{COD} / \mathrm{TN}=10.3 & \mathrm{COD} / \mathrm{TN}=13.8 & \mathrm{COD} / \mathrm{TN}=17.2 \\ \text { Medium TN (MN) } & 57 \mathrm{gN} \mathrm{m}^{-3} & \mathrm{COD} / \mathrm{TN}=7.8 & \mathrm{COD} / \mathrm{TN}=10.4 & \mathrm{COD} / \mathrm{TN}=13.0 \\ \text { High TN (HN) } & 71 \mathrm{gN} \mathrm{m}^{-3} & \mathrm{COD} / \mathrm{TN}=6.3 & \mathrm{COD} / \mathrm{TN}=8.3 & \mathrm{COD} / \mathrm{TN}=10.4\end{array}$

Figure 10 summarizes the results obtained in all these optimizations. The operating cost distributions of each plant and for each influent are represented by the bars, the CHP electric energy recovery has been included as a negative cost, while the net cost is represented by blue dots. A first analysis of the cost distribution shows that positive operating costs are very similar for the conventional and upgraded WWTP, while the C/N/P decoupling WWTP reduces the expenses significantly. For all configurations, these operating costs are mainly associated with influent $\mathrm{N}$ concentration and show a low dependence to the variations of influent $C$ load. In the upgraded and $\mathrm{C} / \mathrm{N} / \mathrm{P}$ decoupling plants, negative operational costs (energy recovery) are increased, due to a more efficient use of the influent COD. Contrarily to the positive costs, energy recovery is mainly associated with $\mathrm{C}$ load and exhibits a very low dependence with the $\mathrm{N}$ concentration in the influent (except for the critical case of very low $\mathrm{C} / \mathrm{N}$ ratio in the conventional plant). Finally, total costs are clearly positive in a conventional plant, while the upgraded configurations could theoretically get a neutral cost balance only for high $\mathrm{C} / \mathrm{N}$ load ratios. However, the $\mathrm{C} / \mathrm{N} / \mathrm{P}$ decoupling plant has a real potential for obtaining a negative cost balance for a broad range of influent characteristics.

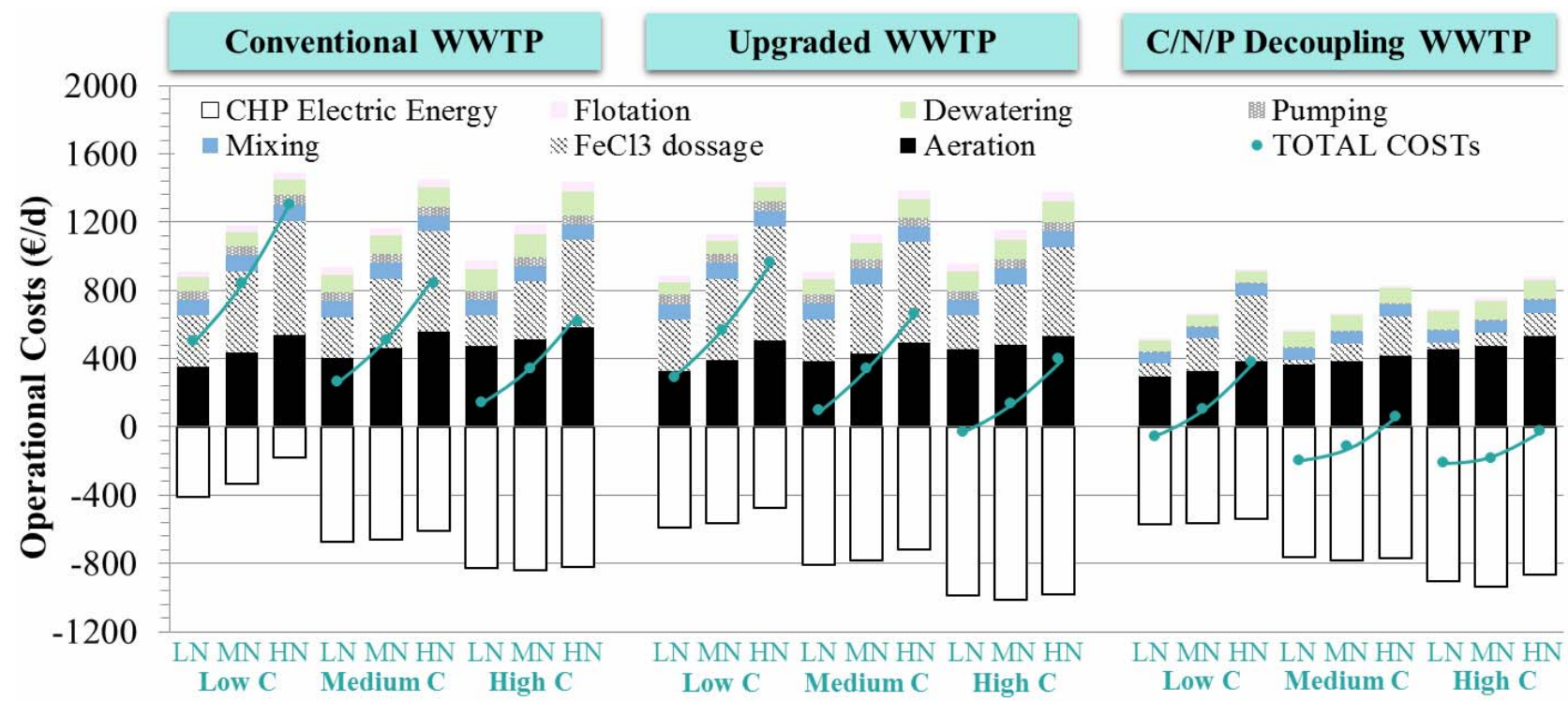

Figure 10. Operating cost analysis in a conventional, upgraded and C/N/P decoupled WWTP for different COD/TN ratios: Cost distribution in columns and net operating costs represented by the blue dots $(€ / d)$.

Figure 11 shows the effect of influent concentrations on the most representative costs (aeration and dosage costs and electricity production) and on the plant self-sufficiency (\%) for the three plantlayouts under study.

The aeration costs exhibits a logical growing trend in the three configurations for increasing $\mathrm{N}$ and COD loads (Figure 11a). It is also remarkable the very limited influence of $\mathrm{N}$ load to the aeration power in the C/N/P Decoupling WWTP, reflecting the high efficiency of this advanced configuration for the removal of $\mathrm{N}$. The Upgraded plant has incorporated a Nitritation/Anammox process to treat rejected supernatants, reducing overall aeration costs around 6-15\% without sludge pre-treatment processes, and somewhat lower, at around $3-11 \%$, when a thermal hydrolysis is incorporated. For the C/N/P Decoupling plant layout, aeration savings of 16-29\% are achieved for low-medium COD loads and savings of $4-8 \%$ for higher concentrations. 

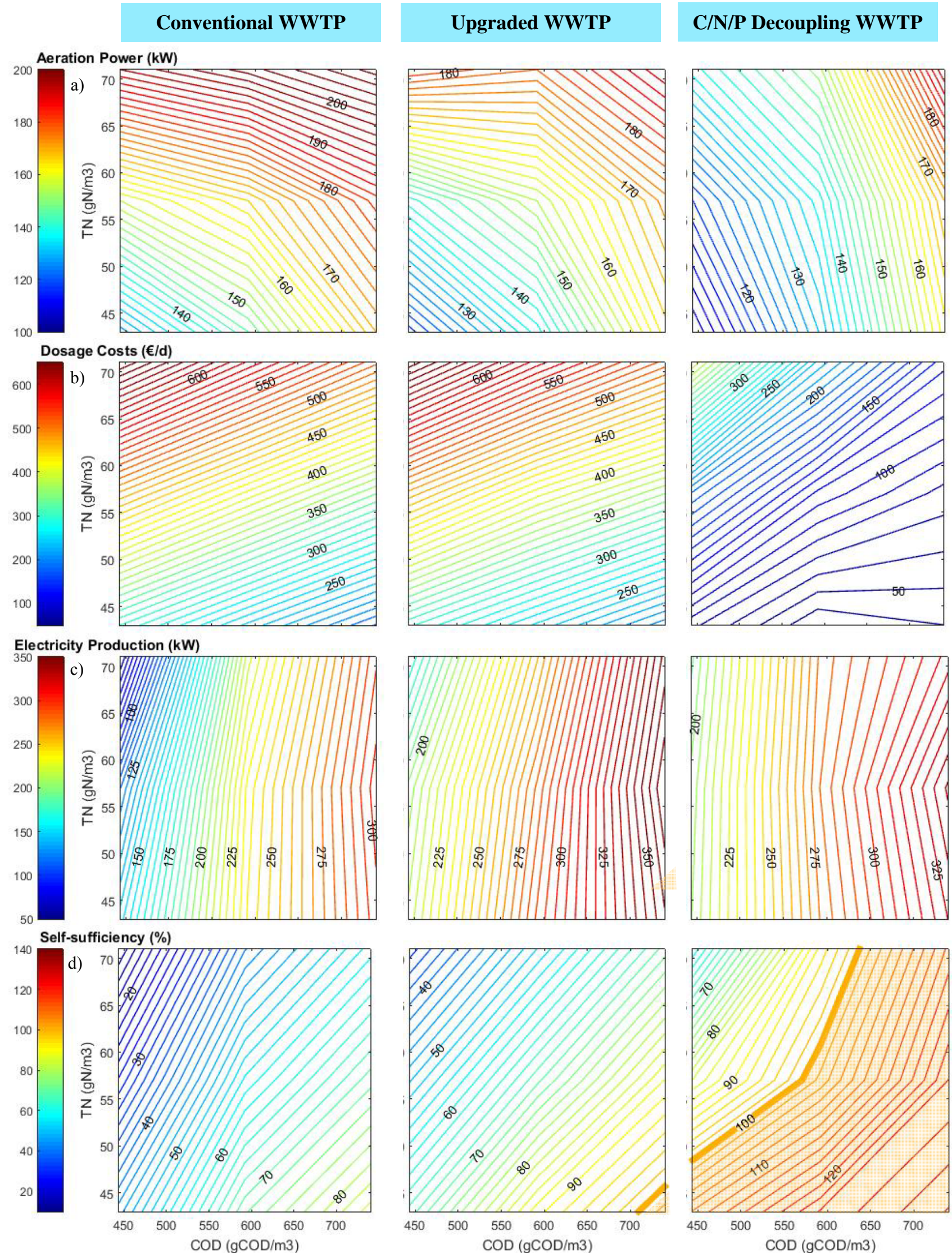

Figure 11. (a) Aeration Power, (b) dosage costs, (c) electricity production, and (d) plant self-sufficiency in a conventional, upgraded and C/N/P decoupled WWTP for different COD/TN ratios

In dosage costs, a similar trend has been also found in the three configurations. Ferric chloride 
dosage depends directly on the influent $\mathrm{P}$ content, but indirectly on the $\mathrm{C} / \mathrm{N}$ ratio. In the first two configurations dosage costs are similar, since in both configurations ferric chloride is used to remove all the phosphorus. The third configuration in turn provides savings in chemical reagents, $78-80 \%$ for high $\mathrm{C} / \mathrm{N}$ ratios and savings of $42-61 \%$ for low ratios. Phosphorus removal is performed through biological reactions, and chemical agents are only used to adjust the water line effluent and the rejected water (after recovering $85 \%$ of ortho-P as struvite) to effluent quality standards. In addition to the significant reduction in operating costs this configuration provides a value-added product such as the struvite. The analysis didn't consider the costs of production of struvite, but neither the profit after its sale. It was considered a neutral balance. Still, using the Sankey diagrams such as those used in the previous section (Figure 9c), a struvite maximum production of 3.7 $\mathrm{kg}_{\text {struvite }} \mathrm{kgP}_{\text {inf }}{ }^{-1}$ for virtually all influents was estimated. Thus, the third plant minimizes operating costs by promoting the recovery of biological products and maximizing the use of energy.

Analysing Figure 11c, it can be seen, as expected, that the biogas production depends exclusively on the influent COD concentration. The incorporation of the TH process has led to increased biogas production by increasing the biodegradability of the sludge. For both configurations the increased production is close to $20 \%$. Being clear the COD dependence, it is possible to set a ratio to estimate the electrical energy generated in CHP per unit of COD fed to the plant: $0.46 \mathrm{kWh} \mathrm{kgCOD}_{\text {inf }}{ }^{-1}$ for the conventional plant, $0.55 \mathrm{kWh} \mathrm{kgCOD}_{\text {inf }}{ }^{-1}$ for the upgraded plant and $0.52 \mathrm{kWh} \mathrm{kgCOD}_{\text {inf }}{ }^{-1}$ for the $\mathrm{C} / \mathrm{N} / \mathrm{P}$ decoupling WWTP.

Finally, the Figure 11d shows a comparative picture of the self-sufficiency for the three plants. Conventional WWTPs were designed based on traditional biological treatments under a "removal philosophy", being difficult to achieve the total energy self-sufficiency. As shown in Figure 11d, the total self-sufficiency degree is closely linked to the $\mathrm{C} / \mathrm{N}$ influent ratio, and this can vary in the conventional plant from $12 \%$ for very low $\mathrm{COD} / \mathrm{TN}$ ratios, up to $85 \%$ for very high ratios. Consequently, the treatment plant layouts comparison with different influent ratios would not be entirely correct, nor ensuring that a configuration is always self-sufficient without mentioning the influent ratio of the analysed plant (Jenkins et al., 2014). The philosophy of the second configuration is based primarily on increasing energy production in order to achieve a net overall balance closer to self-sufficiency, in this case between $33 \%$ and $103 \%$. In this second configuration it is possible to achieve the self-sufficiency but only with high COD/TN ratios (Figure 11d). Finally, the main objective of the third configuration (C/N/P decoupling WWTP) is the operational costs minimization, by promoting the recovery of bio-products and maximizing the use of energy. With this configuration it is possible to achieve the plant self-sufficiency for almost all COD/TN influent ratios (58\% for low $\mathrm{COD} / \mathrm{N}$ ratios and up to $130 \%$ for high ratios).

\section{DISCUSSION AND CONCLUSIONS}

Plant-Wide simulations allows a thorough, comprehensive and accurate analysis of different plant configurations from an energy and resource recovery perspective. To demonstrate the potential of the tool and the need for simulation analysis, this paper compared three different plants: (1) a conventional WWTP, (2) an upgraded or retrofitted WWTP, and (3) a new WRRF concept known as a $\mathrm{C} / \mathrm{N} / \mathrm{P}$ decoupling WWTP.

Analysing the layouts from a standpoint of resources and energy utilization, a low utilization of the energy content of the components could be observed in all configurations. The only resource that can be recovered efficiently as energy is the organic matter transmitted to the gas phase. The oxidation of the components in the aqueous medium (AS process and nitritation/Anammox technology) releases a large amount of energy as heat that is transmitted to the atmosphere or extracted by the effluent (in these simulations about 37\%). This energy is difficult to recover or the 
recovered energy has a low exergy. Therefore, oxidations in the aqueous medium should be minimized and instead oxidations should be promoted in the gaseous phase. Another key to maximizing the COD energy use is to incorporate technologies that increase sludge biodegradability $\left(\mathrm{X}_{\mathrm{P}} \rightarrow \mathrm{X}_{\mathrm{CH}}, \mathrm{X}_{\mathrm{PR}}, \mathrm{X}_{\mathrm{LI}}\right)$, such as the $\mathrm{TH}$ process incorporated in the second and third layouts. In the conventional plant, the COD used to produce biogas was around $29 \%$. The TH technology increased this to $36 \%$ in the upgraded plant and $34 \%$ in the C/N/P decoupling WWTP. In turn, the process reduced sludge production by $12 \%$ and by $22 \%$, respectively, in these two plants.

Regarding resource recovery methods, $\mathrm{N}$ recovery techniques are really expensive (ion exchange methods or stripping processes), or as in the case of the technique that could compete with the removal processes, struvite precipitation, the $\mathrm{N}$ recovered is minimal $(4 \%$ estimated by the $\mathrm{C} / \mathrm{N} / \mathrm{P}$ decoupling WWTP simulation, Figure 8). In the case of $\mathrm{P}$, the scarcity of natural $\mathrm{P}$ resources converts the recovery of $\mathrm{P}$ in the first alternative. The conventional and the upgraded plants removed $\mathrm{P}$ by $\mathrm{FeCl}_{3}$ precipitation and only the third configuration attempted to recover the $\mathrm{P}$. The maximum estimated struvite recovery was $43 \%$ (Figure 9) and the estimated maximum struvite production was $3.7 \mathrm{~kg}_{\text {struvite }} \mathrm{kgP}_{\text {inf }}^{-1}$ for virtually all influents.

Analysing the costs obtained in the study, it can be seen that WWTP self-sufficiency is closely linked to the influent COD/TN/TP ratio. In all plants the trend was similar, the highest degree of self-sufficiency was obtained for the higher ratio values. Achieving self-sufficiency was not possible in conventional plant, in the upgraded plant it depended on the influent ratio, and in the C/N/P decoupling WWTP layout self-sufficiency was feasible for almost all influents (58\% for low $\mathrm{COD} / \mathrm{TN}$ ratios and up to $130 \%$ for high ratios). Simulations for different influents showed that, as expected, operating costs increased with the influent load. Assessing costs in detail, aeration was the most significant cost in all configurations (36-48\% in the conventional and upgraded plants and $41-65 \%$ in the C/N/P decoupling WWTP) followed by the chemical dosage, especially in the first and second configurations $(20-48 \%$ in the conventional and upgraded plants and $5-28 \%$ in the C/N/P decoupling WWTP). Regarding plant qualities, the differentiating factor of the upgraded WWTP layout was the increased biogas production. The thermal hydrolysis process increased the biodegradability of the secondary sludge by $40 \%$ and electricity production by $19-21 \%$ for medium/high COD concentrations and by $43-162 \%$ for low COD concentrations. The decrease in aeration costs was not significant in this second configuration (3-11\%) due to the $\mathrm{NH}_{\mathrm{X}}-\mathrm{N}$ release in the $\mathrm{TH}$ process $\left(25 \%\right.$ more $\left.\mathrm{NH}_{\mathrm{X}} \mathrm{-N}\right)$, although efficient nitritation/Anammox technologies had been used to treat rejected water. The fundamental feature of the C/N/P decoupling WWTP was the increase in electricity production (savings of $10-20 \%$ for high COD/TN ratios and $39-198 \%$ for low ratios) and the decrease in $\mathrm{FeCl}_{3}$ requirements $(78-80 \%$ for high $\mathrm{COD} / \mathrm{TN}$ ratios and $42-61 \%$ for low ratios) and aeration costs (16-29\% for high $\mathrm{COD} / \mathrm{TN}$ ratios and $4-8 \%$ for low ratios), three qualities that enable the plant self-sufficiency.

Through simulation it has been found that each resource has its optimal way of being treated, and thus the key to maximizing the recovery of resources and energy is the independent treatment of nutrients and $\mathrm{COD}$, valorising the organic matter, and recovering or treating the nutrients.

The plant layouts proposed in this paper are just a sample of the possibilities for upgrading or designing innovative plants, but they have enabled an analysis of the current needs and challenges that need to be addressed. Even so, the methodology presented here is generic and can be used for any other plant. The use of plant-wide models is, in this context, very useful to ensuring that complex plants featuring different technologies can be analysed reliably and that the model faithfully reproduces the plant behaviour, also in terms of energy and chemical consumption. 
NOMENCLATURE

Cost $_{\text {actuator }} \quad$ Actuator cost $\left(€ \mathrm{~d}^{-1}\right)$

Cost $_{\text {Chem }} \quad$ Chemical agent specific cost $\left(€ \mathrm{~kg}^{-1}\right)$

Cost $_{\text {dosage }} \quad$ Dosage cost $\left(€ \mathrm{~d}^{-1}\right)$

Cost $t_{\text {poly }} \quad$ Polyelectrolyte specific cost $\left(€ \mathrm{~kg}^{-1}\right)$

$\mathrm{d}_{\mathrm{p}}$

$\mathrm{D}_{\text {pipe }}$

$\mathrm{D}_{\text {stir }}$

$\mathrm{f}_{\text {moody }}$

$\mathrm{F}_{\text {oversize }}$

$\mathrm{g}$

G

$\overline{\mathrm{H}}_{\mathrm{in}}$

$\overline{\mathrm{H}}_{\text {out }}$

HL

$\mathrm{HL}_{\mathrm{f}}$

$\mathrm{HL}_{1}$

$\mathrm{HL}_{\mathrm{s}}$

$\mathrm{k}_{\text {Chem }}$

$\mathrm{k}_{\text {poly,i }}$

$\mathrm{L}_{\text {pipe }}$

$\overline{\mathbf{m}}_{\mathrm{i}, \mathrm{n}}$

MU

$\mathrm{MW}_{\mathrm{i}}$

$\mathrm{n}_{\text {CEPT }}$

$\mathrm{N}_{\mathrm{js}}$

$\mathrm{N}_{\mathrm{P}}$

$\mathrm{P}_{\mathrm{g} \text {,in }}$

$\mathrm{P}_{\mathrm{g} \text {,out }}$

$\mathrm{Q}_{\mathrm{w}}$

R

S

Submergence

$\mathbf{T}_{\mathrm{i} \text { in }}$

$\mathrm{T}_{\text {i.eut }}$

$\mathrm{TSS}_{\mathrm{i}}$

$\mathrm{u}_{\mathrm{w}}$

$\mathrm{V}_{\mathrm{i}}$

$\mathrm{W}_{\text {actuator }}$

$\mathrm{W}_{\text {blow }}$

$\mathrm{W}_{\text {pump }}$

$\mathrm{W}_{\text {stir }}$

$\mathrm{W}_{\text {turbine }}$

Particle size (m)

Pipe diameter $(\mathrm{m})$

Impeller diameter (m)

Friction coefficient

Oversize factor

Gravitational acceleration $\left(\mathrm{m} \mathrm{s}^{-2}\right)$

Velocity gradient $\left(\mathrm{s}^{-1}\right)$

Input enthalpy $\left(\mathrm{kJ} \mathrm{d}^{-1}\right)$

Output enthalpy $\left(\mathrm{kJ} \mathrm{d}^{-1}\right)$

Total head loss (m)

Friction head loss (m)

Minor losses (m)

Static head (m)

Dosage constant $\left(\mathrm{g}_{\text {chem }} \mathrm{m}^{-3}\right)$

Polyelectrolite and Total solids concentration ratio for the sludge type $\mathrm{i}\left(\mathrm{g}_{\text {poly }} \mathrm{kg}_{\mathrm{TSS}}{ }^{-1}\right.$ )

Pipe length (m)

Inlet i phase mass flux $\left(\mathrm{gE} \mathrm{d}^{-1}\right)$

Monetary unit $\left(€ \mathrm{~d}^{-1}\right)$

Molecular weight of i gaseous phase components

Chemically Enhanced Primary Treatment constant

Impeller rotational speed required to just suspend the particles (Hz, revolutions per sec.)

Power number

Absolute gas pressure at the blower/compressor inlet

Absolute gas pressure at the blower/compressor outlet

Water flow rate $\left(\mathrm{m}^{3} \mathrm{~d}^{-1}\right)$

Ideal gas constant $\left(\mathrm{kJ} \mathrm{mol}^{-1} \mathrm{~K}^{-1}\right)$

Impeller/tank geometry factor

Submergence (m)

i phase inflow temperature $(\mathrm{K})$

i phase outflow temperature $(\mathrm{K})$

Total suspended solids concentration in the phase $\mathrm{i}\left(\mathrm{gSS} \mathrm{m}^{-3}\right)$

Average liquid velocity $\left(\mathrm{m} \mathrm{s}^{-1}\right)$

Volume of the i phase $\left(\mathrm{m}^{3}\right)$

Electrical consumption of actuator $\left(\mathrm{kJ} \mathrm{d}^{-1}\right)$

Electrical consumption of blower or compressors $\left(\mathrm{kJ} \mathrm{d}^{-1}\right)$

Electrical consumption of pump $\left(\mathrm{kJ} \mathrm{d}^{-1}\right)$

Electrical consumption of stirring $\left(\mathrm{kJ} \mathrm{d}^{-1}\right)$

Electrical consumption of turbine $\left(\mathrm{kJ} \mathrm{d}^{-1}\right)$

$\mathrm{X}_{\mathrm{TSS}}$

Weight percentage of solids in the suspension

\section{Greek Symbols}

$\gamma_{\mathrm{g}, \mathrm{i}}$

$\eta_{\mathrm{i}}$

$\eta_{\text {blow }}$

$\eta_{\text {CEPT }}$

$\eta_{\max }$

$\eta_{\min }$

$\eta_{\text {pump }}$

$\eta_{\text {stir }}$

$\eta_{\text {turb }}$

$\mathbf{u}_{\mathrm{i}}$

$\varphi_{\mathrm{i}}$

\section{Subscripts}

comp

$\mathrm{g}$

$\mathrm{m}$

$\mathrm{S}$

W

Heat capacity ratio of the $i$ gaseous phase components

Dynamic viscosity $\left(\mathrm{kg} \mathrm{m}^{-1} \mathrm{~s}^{-1}\right)$

Efficiency of blowers/compressors

Chemically Enhanced Primary Treatment efficiency

Chemically Enhanced Primary Treatment maximum efficiency

Chemically Enhanced Primary Treatment minimum efficiency

Efficiency of pumps

Efficiency of agitation engines

Efficiency of turbines

Kinematic viscosity of the i phase $\left(\mathrm{m}^{2} \mathrm{~s}^{-1}\right)$

Density $\left(\mathrm{g} \mathrm{m}^{-3}\right)$

phase components

gaseous phase

No. of state variables in the off-gas phase

solid phase

Aqueous phase 


\section{ACKNOWLEDGEMENTS}

The authors would like to acknowledge COST Action ES1202: Conceiving Wastewater Treatment in 2020 - "Water2020" and RedNovedar (CTQ1914-51693-REDC). S. Puig and M. Poch would like to thank the Spanish Ministry (CTQ2014-53718-R) and the University of Girona (MPCUdG2016/137) for their financial support. LEQUIA has been recognised as a consolidated research group by the Catalan Government (2014-SGR-1168).

\section{References}

Alekseikoa, L.N., Slesarenkob, V.V., Yudakovc, A.A., 2014. Combination of wastewater treatment plants and heat pumps. Pacific Science Review, 16(1), 36-39.

Batstone, D.J., Hülsen, T., Mehta, C.M., Keller, J., 2015. Platforms for energy and nutrient recovery from domestic wastewater: A review. Chemosphere, 140, 2-11.

Batstone, D.J., Virdis, B., 2014. The role of anaerobic digestion in the emerging energy economy. Current opinion in Biotechnology, 27, 142-149.

Batstone D.J., Keller J., Angelidaki I., Kalyuzhnyi S.V., Pavlostathis S.G., Rozzi A., Sanders W.T.M., Siegrist H., Vavilin V.A. 2002. Anaerobic Digestion Model No. 1. Scientific and Technical Report No. 13. IWA Publishing, London.

Bisinella de Faria, A.B., Spérandio, M., Ahmadi, A., Tiruta-Barna, L., 2015. Evaluation of new alternatives in wastewater treatment plants based on dynamic modelling and life cycle assessment (DM-LCA). Water Research, 84, 99-111.

Camp, T.R., Stein, P.C., 1943. Velocity gradients and internal work in fluid motion. J. Boston Soc. Of Civil Eng., 30(4), 219-237.

Cao, Y.S., 2011. Mass flow and energy efficiency of municipal wastewater treatment plants. IWA publishing, London.

Castillo, A., Cheali, P., Gómez, V., Comas, J., Poch, M., Sin, G., 2016. An integrated knowledgebased and optimization tool for the sustainable selection of wastewater treatment process concepts. Environmental Modelling \& Software, 84, 177-192.

CEDEX, 2004. Curso sobre tratamiento de aguas residuales y explotación de estaciones depuradoras. Madrid. Vol. I. (in Spanish)

Corbala-Robles, L., Volcke, E.I., Samijn, A., Ronsse, F., Pieters, J.G., 2016. Effect of foam on temperature prediction and heat recovery potential from biological wastewater treatment. Water Research, 95, 340-347.

Crawford, G., Sandino, J., 2010. Energy efficiency in wastewater treatment in North America: a compendium of best practices and case studies of novel approaches. Report \#OWSO4R07e, Water Environmental Research Foundation and IWA Publishing.

Fernández-Arévalo, T., Grau, P., Jeppsson, U., Mauricio-Iglesias, M., Vrecko, D., Flores-Alsina, X., Ayesa, E., 2017. Model-based comparative assessment of innovative processes. In Lema, J.M., Suarez-Martinez, S. (Eds.), Innovative wastewater treatment \& resource recovery technologies. Impacts on energy, economy and environment, IWA Publishing.

Fernández-Arévalo, T., Lizarralde, I., Grau, P., Ayesa, E., 2016. Diagnostic and optimization of WWTPs using the PWM library: Full-scale experiences. Accepted in Water Science and Technology.

Fernández-Arévalo T., Lizarralde I., Pérez-Elvira S.I., Garrido J.M., Puig S., Poch M., Grau P., Ayesa E., 2015. Conceptual design and comparative assessment of WWTP layouts based on plant-wide model simulations. In: Proceedings of the 9th IWA Symposium on System Analysis and Integrated Assessment (Watermatex15). Gold Coast, Australia, 11-14 June.

Fernández-Arévalo T., Lizarralde I., Grau P., Ayesa E., 2014. New systematic methodology for incorporating dynamic heat transfer modelling in multi-phase biochemical reactors. Water Research, 60, 141-155.

Fernández-Polanco, F., Velázques, R., Pérez-Elvira, S.I., Casas, C., Del Barrio, D., Cantero, F.J., 
Fernández-Polanco, M., Rodríguez, P., Panizo, L., Serrat, J., Rouge, P., 2008. Continuous thermal hydrolysis and energy integration in sludge anaerobic digestion plants. Water Sci. Technol. 57(8), 1221-1226.

Foley, J., de Haas, D., Hartley, K., Lant, P., 2010. Comprehensive life cycle inventories of alternative wastewater treatment systems. Water Res. 44, 1654-1666.

Frijns, J., Hofman, J., Nederlof, M., 2013. The potential of (waste)water as energy carrier. Energy conversion and management, 65, 357-363.

Garrido, J.M., Fdz-Polanco, M., Fdz-Polanco, F., 2014. Working with energy and mass balances: a conceptual framework to understand the limits of municipal wastewater treatment. Water Science \& Tecnology, 67(10), 2294-2301.

Garrido-Baserba, M., Hospido, A., Reif, R., Molinos-Senante, M., Comas, J., Poch, M., 2014. Including the environmental criteria when selecting a wastewater treatment plant. Environmental Modelling \& Software, 56, 74-82.

Gernaey, K.V., Jeppsson, U., Vanrolleghem, P.A., Copp, J. (IWA Task Group on Benchmarking of Control Strategies for Wastewater Treatment Plants), 2014. Benchmarking of Control Strategies for Wastewater Treatment Plants. Scientific and technical report No. 23. IWA publishing, London.

Grau, P., de Gracia, M., Vanrolleghem, P., Ayesa, E., 2007. A new Plant-Wide modelling methodology for WWTPs. Water Research, 41(19), 4357-4372.

Gude, V.G., 2015. Energy and autarky of wastewater treatment and power generation systems. Renewable and sutainable energy reviews, 45, 52-68.

Guest, J.S., Skerlos, S.J., Barnard, J.L., Beck, M.B., Daigger, G.T., Hilger, H., Jackson, S.J., Karvazy, K., Kelly, L., MacPherson, L., Mihelcic, J.R., Pramanik, A., Raskin, L., van Loosdrecht, M.C., Yeh, D., Love, N.G., 2009. A new planning and design paradigm to achieve sustainable resource recovery from wastewater. Environ. Sci. Technol. 43, 6126-6130.

Henze M., Gujer W., Mino T., van Loosdrecht M.C.M. 2000. Activated Sludge Models ASM1, ASM2, ASM2d and ASM3. Scientific and Technical Report N 9 , IWA Publishing, London.

Henze, M., Comeau, Y., 2008. Wastewater Characterization. Biological Wastewater treatment: Principles, Modelling and Design. Edited by Henze, M., van Loosdrecht, M.C.M., Ekama, G.A., Brdjanovic, D. IWA publishing, London, UK.

Hepbasli, A., Biyik, E., Ekren, O., Gunerhan, H., Araz, M., 2014. A key review of wastewater source heat pump (WWSHP) systems. Energy conservation and management, 88, 700-722.

IWA Resource Recovery Cluster, 2015. State of the art compendium report on resource recovery from water. IWA publishing, London.

Jenkins, D., Wanner, J., 2014. Activated sludge - 100 years and counting. IWA publishing, London.

Jeppsson U., Pons M.N., Nopens I., Alex J., Copp J.B., Gerneay K.V., Rosen C., Steyer J.P., Vanrolleghem P.A., 2007. Benchmark simulation model No 2 - general protocol and exploratory case studies. Wat. Sci. Tech., 53(8), 67-78.

Jones, A.V., Clemmet, M., Higton, A., Golding, E., 1999. Access to chemistry. Royal Society of Chemistry. p. 250. ISBN 0-85404-564-3.

Keller, J., 2008. Paradigm shift from wastewater treatment to resource recovery system. AustralianGerman workshop on sustainable urban water management, Melbourne, Australia.

Khiewwijit, R., Temmink, H., Rijnaarts, H., Keesman, K.J., 2015. Energy and nutrient recovery for municipal wastewater treatment: How to design a feasible plant layout? Environmental Modelling \& Software, 68, 156-165.

Kokabian, B., Gude, V.G., 2015. Role of membranes in bioelectrochemical systems. Membr. Water Treat. 6(1), 53-75.Lizarralde I., Fernández-Arévalo T., Brouckaert C.J., Vanrolleghem P.A., Ikumi D.S., Ekama G.A., Ayesa E., Grau P. 2015. A new general methodology for incorporating physico-chemical transformations into multi-phase wastewater treatment process models. Water Research, 74, 239-256. 
Logan, B.E., 2004. Extracting hydrogen and electricity from renewable resources. Environ. Sci, Technol. 38(9), 160-167.

Matassa, S., Batstone, D.J., Huilsen, T., Schnoor, J., Verstraete, W., 2015. Can Direct Conversion of Used Nitrogen to New Feed and Protein Help Feed the World? Environmental Science \& Technology, 49, 5247-5254.

McCarty, P.L., Bae, J., Kim, J., 2011. Domestic wastewater treatment as a net energy producer-can this be achieved? Environ Sci Technol, 45, 7100-7106.

Mininni, G., Laera, G., Bertanza, G., Canato, M., Sbrilli, A., 2015. Mass and energy balances of sludge processing in reference and upgraded wastewater treatment plants. Environ Sci. Pollut Res, 22, 7203-7215.

Nowak, O., 2003. Benchmarking for the energy demand of nutrient removal plants. Water science and technology, 47(12), 125-132.

Nowak, O., Keil, S., Fimml., C., 2011. Water Science \& Technology, 64(1), 1-6.

Pérez-Elvira, S.I., Nieto-Diez, P., Fdz-Polanco, F., 2006. Sludge minimization technologies. Rev. Environ. Sci. Bio Technol., 5, 375-398.

Pagilla, K.R., Nouri, J., 2004. Energy Management in Wastewater Treatment Plants: Optimization of Energy Production, Res. J. Chem. Environ., 8(2), 26-33.

Puchongkawarin, C., Gomez-Mont, C., Stuckey, D.C., Chachuat, B., 2015. Optimization-based methodology for the development of wastewater facilities for energy and nutrient recovery. Chemosphere, 140, 150-158.

Shoener, B.D., Bradley, I.M., Cusick, R.D., Guest, J.S., 2014. Energy positive domestic wastewater treatment: the roles of anaerobic and phototropic technologies. Environ. Sci. Process Impacts, $16,1204-1222$.

Spindler, A., Vanrolleghem, P.A., 2012. Dynamic mass balancing for wastewater treatment data quality control using CUSUM charts. Water Science \& Technology, 65(12), 2148-2153.

Tchobanoglous, G., Stensel, H.D., Tsuchihashi, R., Burton, F., 2014. Wastewater Engineering: Treatment and resource recovery, $5^{\text {th }}$ Ed., McGraw-Hill, New York.

Tik, S., Langlois, S., Vanrolleghem, P.A., 2013. Establishment of control strategies for chemical enhanced primary treatment based on online turbidity data. In: Proceedings $11^{\text {th }}$ IWA Conference on Instrumentation, Control and Automation (ICA2013), 18-20 September, Narbonne, France.

Verstraete, W., Van de Caveye, P., Diamantis, V., 2009. Maximum use of resources present in domestic "used water". Bioresour. Technol. 100(23), 5537-5545.

Verstraete, W., Vlaeminck, S.E., 2011. ZeroWasteWater: short-cycling of wastewater resources for sustainable cities of the future. International Journal of Sustainable Development \& World Ecology, 18(3), 253-264.

Volcke, E.I.P., Gernaey, K.V., Vrecko, D., Jeppsson, U., van Loosdrecht, M.C.M., Vanrolleghem, P.A., 2006. Plant-wide (BSM2) evaluation of reject water treatment with SHARON-Anammox process. Water Sci. Technol. 54(8), 93-100.

Wanner, O., Panagiotidis, V., Clavadetscher, P., Siegrist, H., 2005. Effect of heat recovery from raw wastewater on nitrification and nitrogen removal in activated sludge plants. Water Research, $39,4725-4734$.

Weisbach, J., 1845. Lehrbuch der Ingenieur und Maschinen Mechanik, Vol. 1. Theoretische Mechanik, Vieweg und Sohn, Braunschweig, Germany. 535 pages (in German).

Wett, B., Buchauer, K., Fimml, C., 2007. Energy self-sufficiency as a feasible concept for wastewater treatment system. In: IWA Leading Edge Technology Conference. Asian Water, Singapore, pp. 21-24.

Wilfert, P., Kumar, P.S., Korving, L., Witkamp, G.J., van Loosdrecht, M.C.M., 2015. The relevance of phosphorus and iron chemistry to the recovery of phosphorus from wastewater: A review. Environmental science and technology, 46(16), 9400-9414. 
Zaher, U., Chen, S., Chenlin, L., Yu, L., Ewing, T., 2009. Producing Energy and Fertilizer from Organic Municipal Solid Waste: Enhancing Hydrolysis and Bacterial Populations and Mixing and Thermodynamic Modeling of New Solid Waste Treatment Technology. Ecology Publication Number 09-07-064.

Zwietering, Th.N., 1985. Suspending of solid particles in liquid by agitators. Chemical engineering science, 8, 244-253. 